\title{
Sensitivity of the Earthquake Response of Tall Steel Moment Frame Buildings to Ground
}

Motion Features

\section{Swaminathan Krishnan and Matthew Muto, California Institute of Technology}

\begin{abstract}
The seismic response of two tall steel moment frame buildings and their variants is explored through parametric nonlinear analysis using idealized sawtooth-like ground velocity waveforms, with a characteristic period (T), amplitude (peak ground velocity, $P G V$ ), and duration (number of cycles, $N$ ). Collapse-level response is induced only by long-period, moderate to large $P G V$ ground excitation. This agrees well with a simple energy balance analysis. The collapse initiation regime expands to lower ground motion periods and amplitudes with increasing number of ground motion cycles.
\end{abstract}

\section{1.. Introduction}

Tall steel buildings dominate the skyline of many cities in the western US exposed to serious seismicity from a variety of sources. Consider the case of Los Angeles (LA). As of 2007, there were 489 buildings with 10-19 stories, 118 buildings with 20-29 stories, 28 buildings with 30-39 stories, 11 buildings with 40-49 stories, and 10 buildings with 50 or more stories. Seismic risk to these buildings arises from two sources: well mapped-out strike-slip faults such as the San Andreas, Newport-Inglewood, and Santa Monica-Hollywood-Raymond faults that have some form of surface expression, and the network of blind-thrust faults hidden deep inside the Earth that includes the Northridge fault and the Puente Hills fault underneath downtown Los Angeles. While the San Andreas strike-slip fault system has the potential for large (moment magnitude $~ 8$ ) earthquakes, typically every 200-300 years [35, 34], the blind-thrust faults have the potential for more moderate magnitude $\sim 7$ earthquakes [33]. The diverse source mechanisms of future earthquakes on these faults could result in earthquake shaking with vastly 
different features. These features include frequency content as well as intensity and duration of strong shaking. Adding to the complexity is the presence of deep sedimentary basins where hundreds of tall buildings are sited. The majority of the tall buildings in Los Angeles (607 out of 656) are in the 10-30 story range. In this height range, the steel moment frame system, consisting of a grid of beams and columns rigidly connected together, is the most widely used lateral force-resisting structural system. To quantify the hazard posed to these buildings, it is imperative to identify the combination of features that induce the greatest response in these structures. Of particular interest are the ground motion features that could collapse these massive structures.

Real-world data that could provide insights into these aspects is minimal. There have been only three sizable earthquakes that have struck cities with modern tall steel buildings - the January 17 , 1994, magnitude 6.7, Northridge earthquake, the September 19, 1985, magnitude 7.8, Mexico City earthquake, and the January 17, 1995, Magnitude 6.9, 1995 Kobe earthquake. The Northridge earthquake caused fractures to occur in the connections of many of these buildings [8], but the shaking was not intense enough to cause collapse (most of the energy was directed away from the LA basin into the Santa Susanna mountains [41]). Steel construction is not common in Mexico City. Of the few isolated steel buildings existent there at the time of the 1985 earthquake, two 14- and 21-story towers out of five tall steel frame buildings collapsed in the Conjunto Pino Suarez apartment complex, and, although it remained standing, a third 21-story tower was leaning six feet out of plumb at the roof level. These collapses have been attributed to the strong amplification of the lake bed on which parts of the city are located and the long-period nature of the ground motion [1]. The amplification was enabled by the long duration of the main shock resulting in a resonant buildup of seismic waves within the thick clay layer just beneath the surface. The three identical 21-story structures consisted of five 6m-bays in 
the long direction and two 6m-bays in the short direction. The lateral force-resisting system consisted of moment frames at all column lines with two bays in the short direction braced using $\mathrm{X}$ braces, and one bay in the long direction braced using V braces [31]. Collapse is deemed to have occurred due to weld failure in the built-up box column and subsequent local buckling of the flanges. In addition to demonstrating that even steel highrise structures can collapse, this earthquake brought to the fore the possibility of upper-story collapses in midrise and highrise structures, due in part to the pounding of adjacent buildings, drastic tapering of columns in the upper stories, and more generally to the dynamics of the structural response. The Kobe earthquake strongly shook many welded steel moment frame buildings ranging from lowrise buildings constructed in the 1950s and 1960s to modern highrise structures constructed within the preceding 10 years. While the design and construction of these buildings are significantly different from that in the US, the extent of damage observed in steel structures in this earthquake once again point to the possibility of a set of unfortunate factors leading to disastrous consequences. Out of 630 modern steel buildings in the heavily shaken area, the Building Research Institute determined that approximately one-third experienced no significant damage, one-third relatively minor damage, and the remaining third severe damage, including partial or total collapses of approximately half of these buildings [7,8].

These three earthquakes, despite providing very useful insights into steel building vulnerabilities, do not provide a complete picture of all the conditions that could result in collapse, especially in the taller steel buildings. For this, a systematic sensitivity analysis of these buildings under earthquake excitation is needed. Challa and Hall [4] conducted a series of 2-D nonlinear analyses on a 20-story building using six idealized pulse-like ground motions that are similar to pulses in near-fault ground motion records. MacRae [25] and Gupta and Krawinkler [10, 11] analyzed 20-story steel moment 
frame models under a suite of 20 ground motion records compiled by Somerville et al. [36] and determined the structural response as a function of the spectral acceleration at the fundamental period of the building. The buildings were designed to be hypothetically sited in Los Angeles, Seattle, and Boston. Several research groups tried modeling the damage to an 18-story steel frame building during the Northridge earthquake of 1994 (e.g., [5, 3]). Medina and Krawinkler [27, 28] evaluated the drift demands and their associated uncertainties in non-deteriorating regular moment resisting frames subjected to ordinary ground motions, i.e., without near-fault effects. Krishnan [15] studied the response of four 19-story steel moment frame buildings with irregular configurations under near-source ground motion from the 1994 Northridge, the 1995 Kobe, and the 1978 Iran earthquakes.

More recently, incremental dynamic analysis [40] has been used to assess the collapse capacity as a function of the spectral acceleration at the fundamental period of the building (e.g., [44, 45, 46]). In this approach, a structure is analyzed under progressively scaled-up ground motion records and its response is computed. The spectral acceleration level at which structural response becomes unbounded is the collapse capacity of the building. Finally, the emergence of rupture-to-rafters simulations [24] has led to extensive investigations on the performance of tall steel moment frame buildings under large simulated earthquakes in Los Angeles, San Francisco, and Seattle (e.g., [21, 30, 43, 29]).

All these analyses provide insights into the nature of ground motions that might collapse a tall steel moment frame building. However, they are not comprehensive and systematic in exploring the ground motion parameter space uniformly. This is because a limited number of records are used that span a narrow band of frequency, intensity, and duration. Moreover, a single ground motion intensity measure (e.g., spectral acceleration at the building fundamental period) is used to relate the structural response to ground motion features. This generally leads to a large scatter in the results 
of the simulations - a reflection of the inability of this single measure to adequately capture all the features of ground motions to which these buildings are sensitive to.

\subsection{Study Objective and Approach}

The objective of this study is to determine the sensitivity of the collapse regime of tall steel moment frame building response to three ground motion features- frequency content, intensity, and duration. A straightforward approach to achieving this objective is to: (i) develop a simplified (idealized) representation scheme for seismic ground motion waveforms using three parameters to characterize ground motion frequency content, intensity, and duration; (ii) conduct a parametric nonlinear response history analysis sweep of selected tall building models by varying the parameters of the idealized waveforms; such a suite of analyses can help to systematically and uniformly explore structural response to ground motions with features spanning a broad spectrum, covering earthquakes of all kinds; (iii) create a database of key structural response metrics as a function of ground excitation waveform parameters; and (iv) map the key structural response metrics that track collapse (transient and peak residual interstory drift ratio) against the idealized waveform parameters. A necessary condition for the findings to be equally applicable to real seismic ground motion is that the structural response under the best-fit idealized ground excitation must closely mimic that under the true waveform being emulated. This condition forms the basis for the selection of the ground motion idealization scheme.

\subsection{Buildings Considered and Modeling Details}

Here, we focus on two tall steel moment frame buildings and their variants. The first building is an existing 18-story office building, located within five miles of the epicenter of the 1994 Northridge earthquake. An isometric view of its FRAME3D model is shown in Figure 1(a). It was designed 
according to the 1982 Uniform Building Code (UBC) and completed in 1986-87. The height of the building above ground is $75.7 \mathrm{~m}$ (248' 4") with a typical story height of $3.96 \mathrm{~m}$ (13' 0") and taller first, seventeenth, and penthouse stories. The lateral force-resisting system consists of two-bay welded steel moment-frames, two apiece in either principal direction of the structure as shown in Figure 1(b). The location of the north frame one bay inside of the perimeter gives rise to some torsional eccentricity. Many moment-frame beam-column connections in the building fractured during the Northridge earthquake, and the building has been extensively investigated since then by engineering research groups $[32,5,3]$. Fundamental periods, computed assuming $100 \%$ dead load and $30 \%$ live load contribution to the mass, are 4.52s (X-translation), 4.26s (Y-translation) and 2.69s (torsion). We consider two models of the existing building, one with connections susceptible to fracture, and the other with perfect connections (premature fracture is excluded). Two orthogonal orientations (with respect to the strong component of the ground motion) are considered for the model with perfect connections.

The second building, a FRAME3D model of which is shown in Figure 1(c), is similar to the existing building, but the lateral force-resisting system has been redesigned according to the 1997 UBC. It has been designed for larger earthquake forces and greater redundancy in the lateral forceresisting system, with 8 bays of moment-frames in either direction (although lateral resistance will likely be dominated by the three-bay moment frames shown in Figure 1(d) as opposed to the singlebay moment frames). The frame located in the interior of the existing building has been relocated to the exterior, eliminating the torsional eccentricity. Fundamental periods, computed assuming $100 \%$ dead load and 30\% live load contribution to the mass, are 4.06s ([X+Y-] translation), 3.85s $([\mathrm{X}+\mathrm{Y}+]$ translation) and 2.60s (torsion). The positive (+) directions of the $\mathrm{X}$ and $\mathrm{Y}$ axes are shown on the plans (Figure 1). Note that the fundamental translational modes are oriented approximately along the 


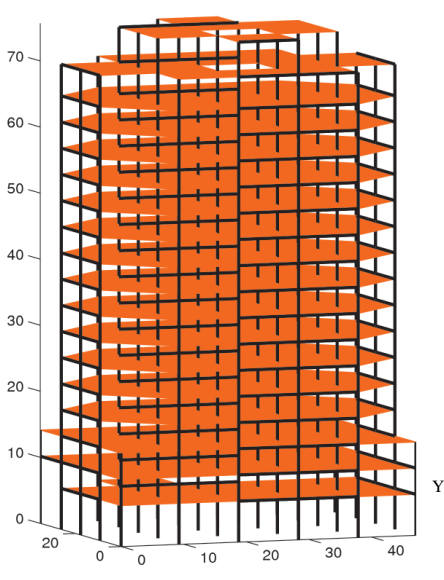

(a)

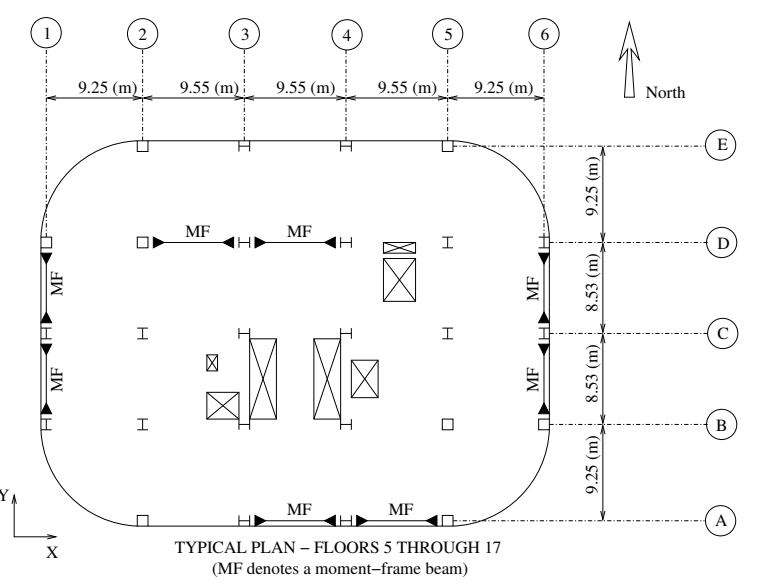

(b)

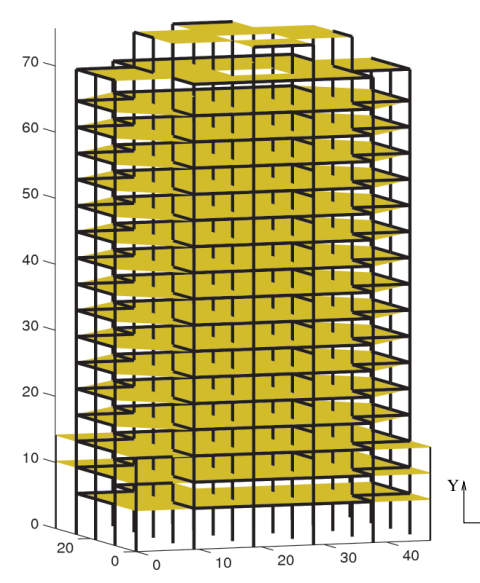

(c)

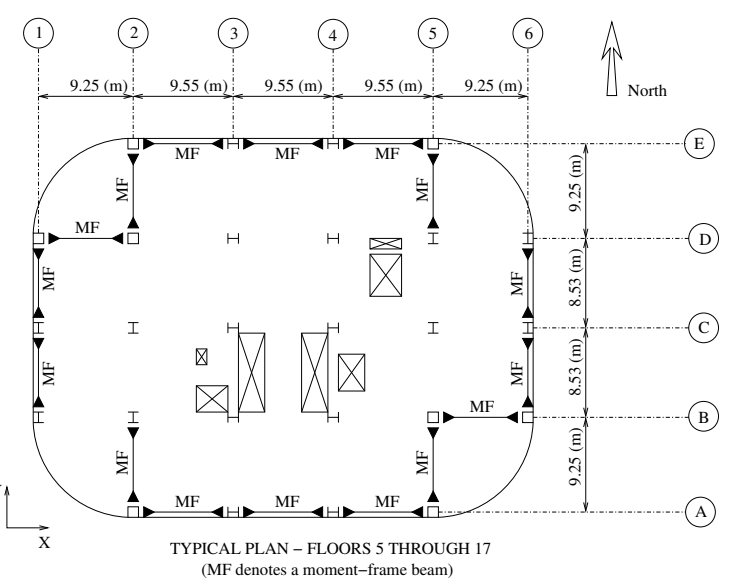

(d)

Figure 1: Structural models of the two 18-story steel moment frame buildings: (a) Isometric view of the existing building (designed using the 1982 UBC). (b) Plan view of a typical floor of the existing building showing the location of columns and moment-frame (MF) beams. (c) Isometric view of the new building (redesigned using the 1997 UBC). (d) Plan view of a typical floor of the redesigned building.

floor plate diagonals. This is because the L-shaped layout of the moment frames at opposite corners of the building, the use of box columns at the corners along one diagonal and I-sections for columns at the corners along the other diagonal, and the absence of X-direction beams in two bays located at diagonally opposite corners create two axes of symmetry (one strong and one weak) that are oriented roughly along the floor plate diagonals. Detailed floor plans, beam and column sizes, and the gravity, wind and seismic loading criteria for the two buildings can be found in [20]. Only one variant of the redesigned building is modeled here, that with perfect connections. 


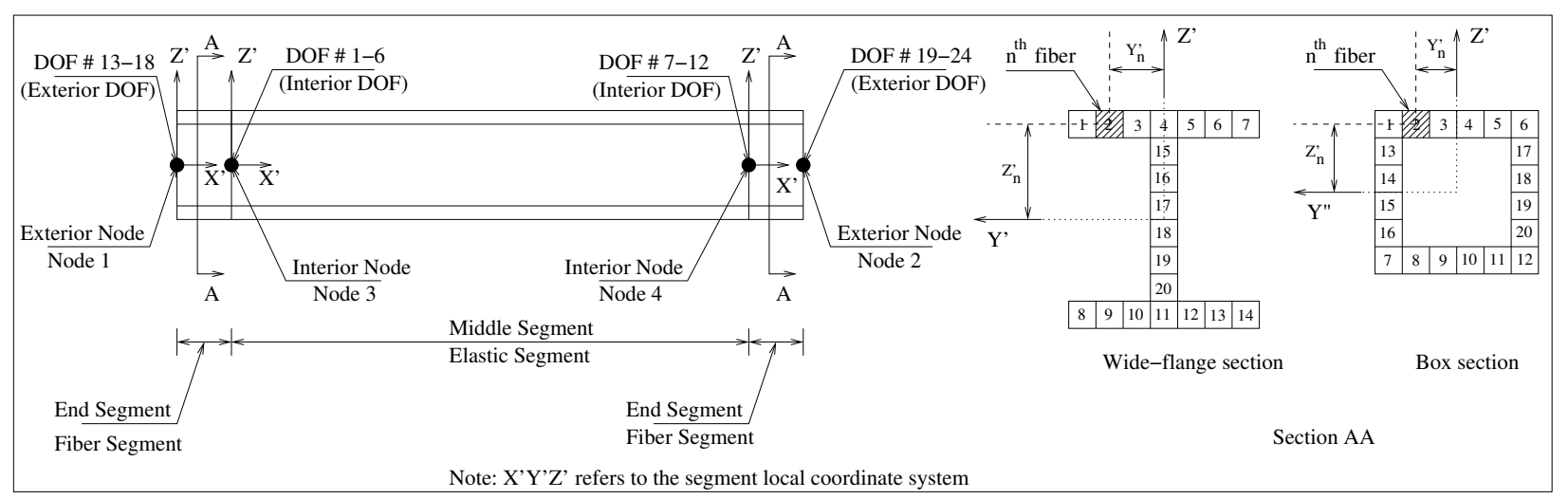

Figure 2: Schematic representation of the elastofiber beam element used to model columns and beams. Each element is divided into a linear elastic middle segment and two non-linear fiber segments.

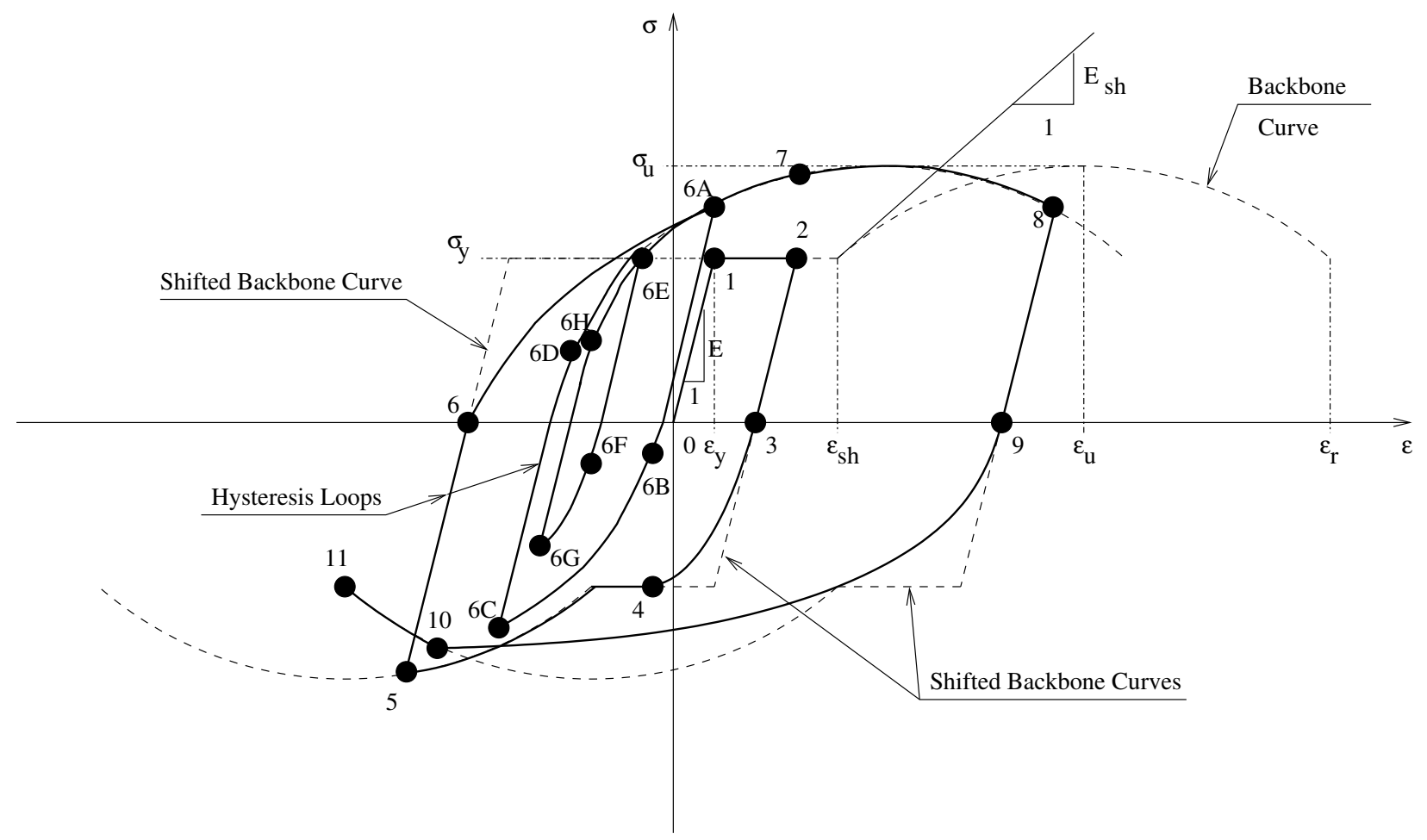

Figure 3: An example of the fiber response in an elastofiber element.

The buildings are modeled using our 3-D nonlinear time history analysis software, FRAME3D (http://virtualshaker.caltech.edu), which has been extensively validated against analytical solutions of simple problems and cyclic data from component tests, as well as pseudodynamic full-scale tests of assembled structures [14, 18, 19, 16, 17]. FRAME3D incorporates material and geometric nonlinearity, which enables the modeling of the global stability of the building, fully ac- 
counting for $P-\Delta$ effects accurately. Beams are modeled using segmented elastofiber elements, with nonlinear end segments that are subdivided in the cross section into a number of fibers, and an interior elastic segment as shown in Figure 2. The stress-strain response of each fiber in the nonlinear end-segment is hysteretic, including flexural yielding, strain-hardening and ultimately rupture of the fiber, as shown in Figure 3. Since strength and stiffness of the end segments of beams and columns are integrals of the corresponding quantities over all the fibers comprising the segment, they too can degrade as the stresses in the fibers exceed the ultimate stress and traverse the downhill path to rupture. In the extreme event that all the fibers of the end segment rupture, there will be a complete severing of the column or beam. There is great uncertainty in the performance of the beam-to-column connections in older welded steel moment frame buildings as evidenced in the 1994 Northridge earthquake, where brittle behavior was observed in many of these connections. To take into account this vulnerability of older steel moment-frames to fracture, FRAME3D allows for a user-specified probabilistic description of the fracture strain of fibers in elastofiber elements. While fibers can fracture at randomly selected strain levels, low-cycle fatigue is not explicitly included. Neither is local buckling of column flanges. Beam-to-column joints are modeled in three dimensions using panel zone elements that include shear yielding (Figure 4). These elements have been shown to simulate damage accurately and efficiently. Results of pushover analysis in either direction of all three models (existing building with susceptible and perfect connections, and redesigned building with perfect connections), with the models being subjected to a slow, ramped, horizontal ground acceleration that increases at a constant rate of $0.3 \mathrm{~g} /$ minute, and structural response being computed dynamically using FRAME3D, are presented in 


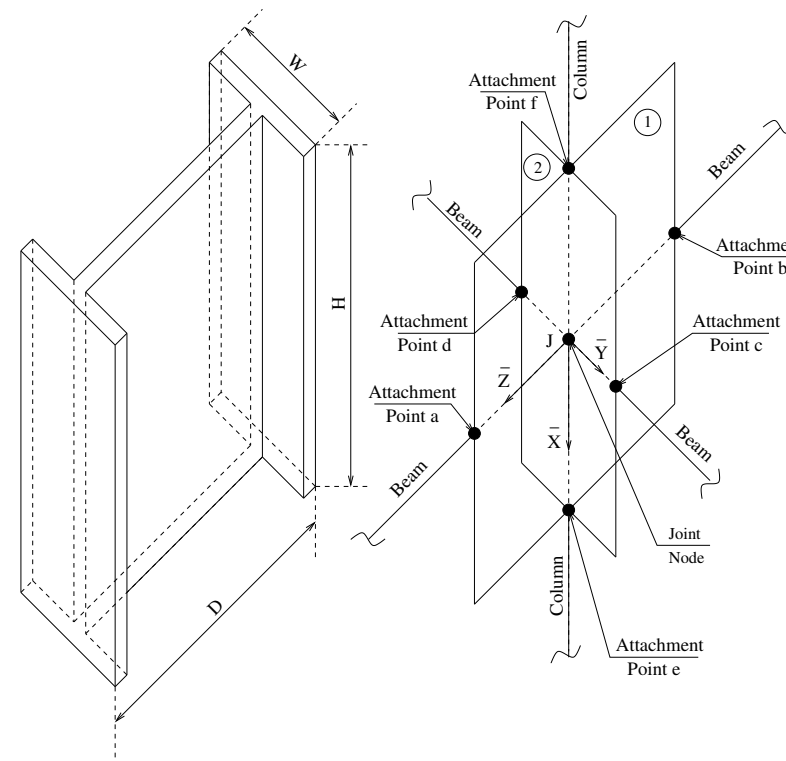

(a)

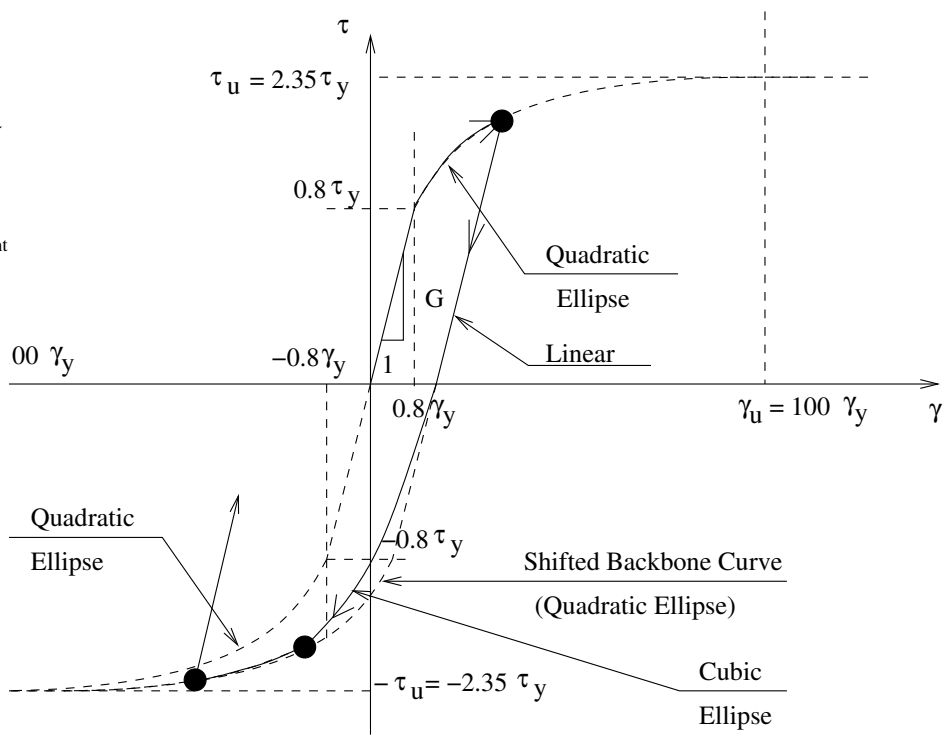

(b)

Figure 4: (a) Idealization of the beam-column connection into a panel-zone element. (b) Backbone curve for the nonlinear hysteretic stress-strain relationship in the panel-zone element.

Figure $5^{1}$. The structural models are identical to those used for ground motion analyses except that masses for the horizontal degrees of freedom are recalculated such that their sum matches the total seismic-design mass, W/g, with a distribution that is proportional to the 1997 UBC seismic static design loads. Thus, the lateral loads are essentially proportional to the horizontal seismic design forces over the height of the structure increasing with time at a slow rate.

\section{2.. Ground Motion Idealization}

Tall buildings of the kind targeted in this study are long-period structures and are generally more responsive to long-period ground excitation. High frequency content in the ground motion has little influence on their collapse behavior [21]. The power in the long-period regime is more apparent in

\footnotetext{
${ }^{1}$ Similar figures showing results of pushover analysis of these buildings, presented in an earlier paper [21], were erroneous. The errors associated with the fracture-susceptible connection model were caused by an error in the implementation of fiber fracture in FRAME3D. This error had a significant effect on pushover analysis alone. It had negligible impact on the dynamic analyses of the existing building model presented in that paper. The errors associated with the redesigned building model were caused by input errors related to panel zone element orientations. These errors affected not only the pushover analysis results, but also the dynamic analysis results presented therein. The peak interstory drift ratios for the dynamic analyses of the redesigned building model in that study should be reduced by about $25 \%$ on the average.
} 


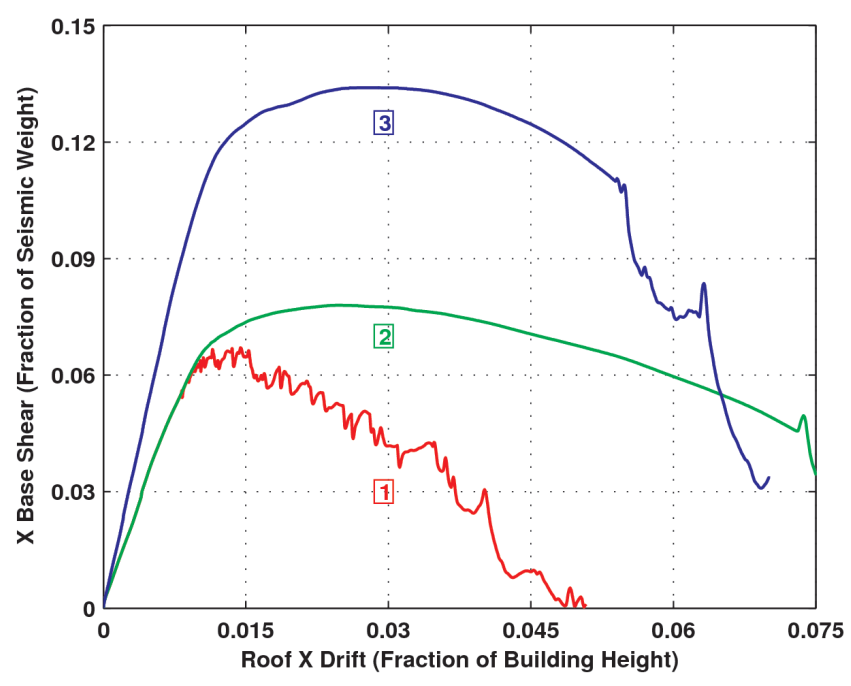

(a)

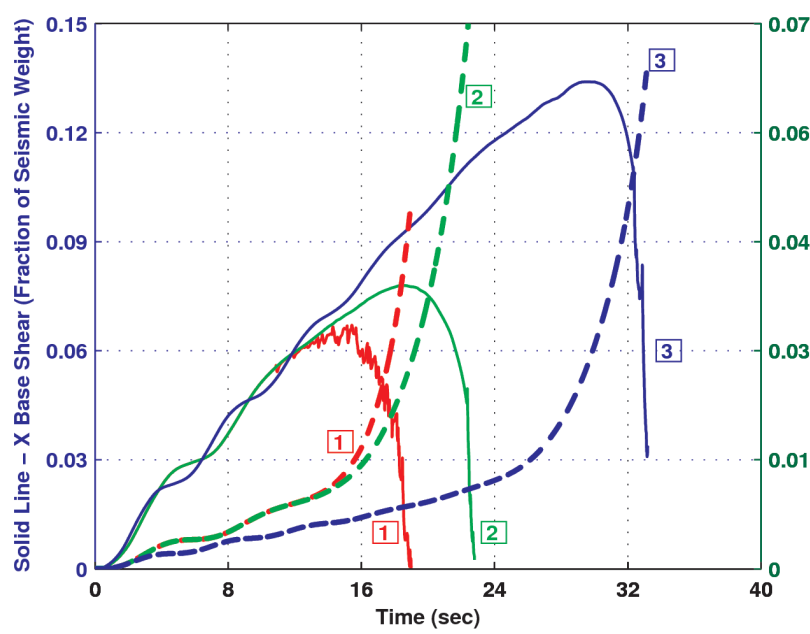

(c)

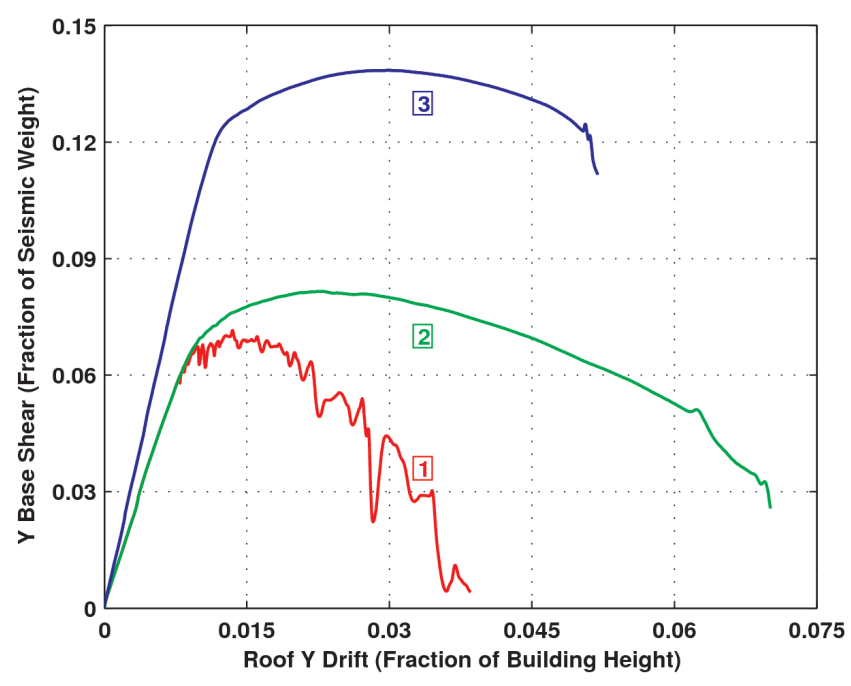

(b)

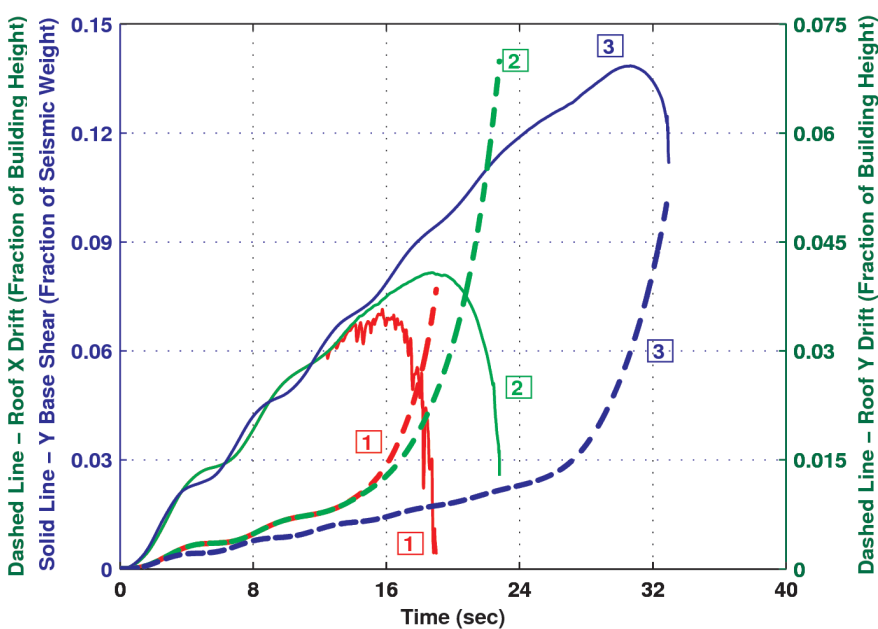

(d)

Figure 5: Pushover analysis of the existing building model with fracture-susceptible connections (curves labeled [1]), the existing building model with perfect connections (curves labeled [2]) and the redesigned building model with perfect connections (curves labeled [3]). (a) X-direction pushover - roof displacement versus base shear. (b) Y-direction pushover - roof displacement versus base shear. (c) X-direction pushover - base shear (solid lines) and roof displacements (dashed lines) as functions of time. (d) Y-direction pushover - base shear (solid lines) and roof displacements (dashed lines) as functions of time.

ground velocity and displacement waveforms than in the ground acceleration waveform that is dominated by the higher frequencies. Thus, structural damage to tall buildings is better correlated with peak ground velocity $(P G V)$ and peak ground displacement $(P G D)$ than with peak ground acceleration $(P G A)$. The collapse of the tall buildings in Mexico City at a distance of over $350 \mathrm{~km}$ from the epicen- 
ter of the Mexico City earthquake of 1985 is testament to this fact. The amplitudes of high-frequency ground accelerations had attenuated significantly due to the large propagation distance. However, the seismic waves retained significant energy at longer periods. As alluded to previously, what caused these buildings to collapse is the amplification of this long-period excitation (growth of $P G D$ and $P G V$ in the $2 \mathrm{~s}-3 \mathrm{~s}$ period range) as the waves propagated through the thick clay layer just beneath the surface upon which they were located [1]. This sensitivity of tall building response to $P G V$ and $P G D$ (in addition to duration) suggests that ground velocity and displacement waveforms are best candidates for parameterization, as far as applicability to tall buildings is concerned. Displacement waveforms have one drawback however. They can have static offsets that may (if they occur quickly) or may not (if they occur slowly) have a significant influence on tall building response. Characterizing the static offset may require one or two additional parameters, increasing the complexity of the parameterization scheme; so this approach was not pursued in this study. On the other hand, residual ground velocities following an earthquake are always zero, making ground velocity waveforms the best candidate for parameterization. Here, ground velocity waveforms are idealized as triangular (sawtooth-like) wavetrains as shown in Figure 6(b). This ground motion representation scheme was first used by Hall et al. [12] to study the effects of near-source ground motion on tall building response. The displacement history in this representation [Figure 6(a)] closely mimics the displacement pulse that would result from the rupture of a penny-shaped crack on a fault surface (point-source) in the vicinity of the crack. Although a single cycle is shown in the figure, multi-cycle extensions with identical period and amplitude are also used to represent long-duration ground motion waveforms. The acceleration waveform corresponding to this velocity history is a rectangular wave-train [Figure 6(c)], while the displacement is a one-sided parabolic wave-train [Figure 6(a)]. The one-sided nature of the displacement should not be of concern. For multi-cycle excitation, displacement is cyclic but always has a positive sign. This 


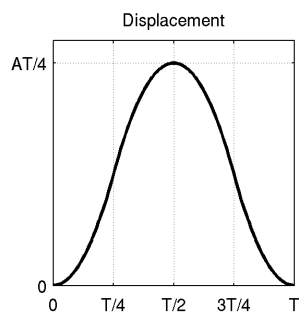

(a)

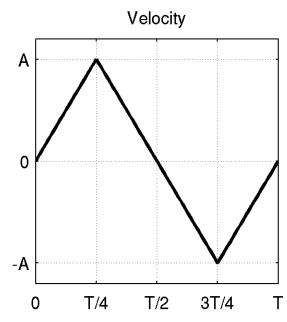

(b)

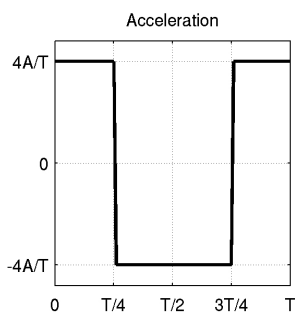

(c)

Figure 6: Waveforms for the (a) displacement, (b) velocity, and (c) acceleration of the idealized pulses used as input ground motions.

is an artifact of the idealization scheme, mathematically equivalent to shifting the origin of the frame of reference, and should have little or no effect on the dynamics of the structure ${ }^{2}$.

Three parameters are used to characterize the ground velocity waveform: period $T$, amplitude $P G V$ (peak ground velocity), and number of cycles $N$. The ability of this ground motion representation to accurately emulate the true seismic ground motion waveforms, as far as impacts on the buildings of interest are concerned, must be ensured. Toward this end, the best-fitting single-cycle idealized waveform from a suite of idealized waveforms to the strong component (with largest $P G V$ ) of 18 near-source records (velocity histories) is determined using the Least Absolute Deviation method ( $L_{1}$ norm). The $L_{1}$ norm (least absolute deviation) accords equal weightage to the amplitude as well as period of ground motion during the minimization process, unlike the $L_{2}$ norm (least squares) which would accord far greater weightage to the amplitude than the period. Since structural response is sensitive to both periods and amplitudes, the $L_{1}$ norm is used. The idealized waveform suite comprises

\footnotetext{
${ }^{2}$ The one-sided displacement history shown in Figure 2(c) can be made two-sided by simply shifting the baseline by an amount equal to half the peak ground displacement, i.e., performing a transformation $v_{g}=v_{g}-P G D / 2$, where $v_{g}$ is the ground displacement as a function of time. Mathematically, this transformation will not result in a change in either the ground velocity history or the acceleration history (because the first and second derivatives of this constant shift would be zero). Since the forcing term in the dynamic equations of motion solved by FRAME3D involves only ground acceleration, this term remains unchanged under such a baseline shift of the displacement history. Therefore, this baseline shift in the displacement (equivalent to physically relocating the structure by a distance equal to half the peak ground displacement and exciting the relocated structure by a displacement wave that has equal positive and negative displacement amplitudes) will not affect the results of the dynamic analysis. It should be noted that the structure is still oscillating back and forth about its vertical line of plumb (since the ground acceleration is cyclic with equal negative and positive amplitudes).
} 
of waveforms with period varying between $0.5 \mathrm{~s}$ and $6.0 \mathrm{~s}$ at $0.25 \mathrm{~s}$ intervals, $P G V$ varying between $0.125 \mathrm{~m} / \mathrm{s}$ and $2.5 \mathrm{~m} / \mathrm{s}$ at $0.125 \mathrm{~m} / \mathrm{s}$ intervals, and the number of cycles ranging from 1 to 5 as well as 10 to emulate long duration records. The near-source records are from the 1971 San Fernando, the 1978 Iran, the 1979 Imperial Valley, the 1987 Superstition Hills, the 1989 Loma Prieta, the 1992 Cape Mendocino, the 1992 Landers, the 1994 Northridge, the 1995 Kobe, and the 1999 Chi-Chi earthquakes. The idealized waveform fits for 2 cases are shown in Figure 7. Best-fitting 2-, 3-, 4-, 5-, and 10-cycle waveforms are shown as well. These are not utilized in the forthcoming analysis since all the records have a prominent near-source pulse that is likely to dominate the structural response. They are, however, used in characterizing ordinary multi-cycle ground motion in later sections. The fits for the remaining 16 cases can be found in [22].

The FRAME3D models of the existing building (perfect and susceptible connections), and the redesigned building (perfect connections) are analyzed under the 18 three-component near-source records. For the existing building model with susceptible connections and the redesigned building model with perfect connections, the strong component of ground motion (with largest $P G V$ ) is oriented in the building $\mathrm{X}$ direction. For the existing building model with perfect connections, two analysis cases are considered. In the first case, the strong ground motion component is oriented in the building $\mathrm{X}$ direction and the weak component is oriented in the building $\mathrm{Y}$ direction. In the second case, the ground motion horizontal components are swapped. The peak transient interstory drift ratio (IDR), which is the peak value for all stories of the relative displacement between the top and bottom of a story normalized by its height, is used as a measure of structural performance. It is a good indicator of damage to both structural elements (plasticity and fracture) as well as many types of nonstructural elements. The same models are also analyzed under the one-component best-fitting single-cycle ide- 


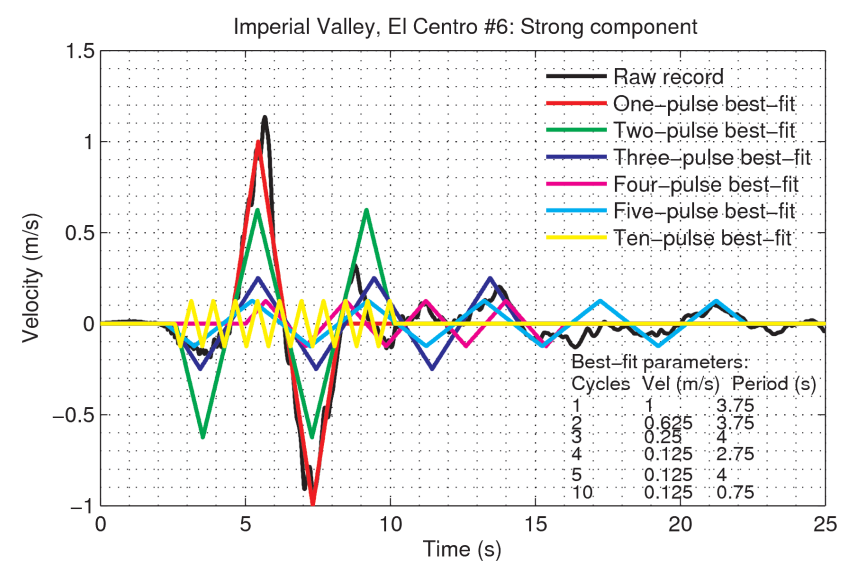

(a)

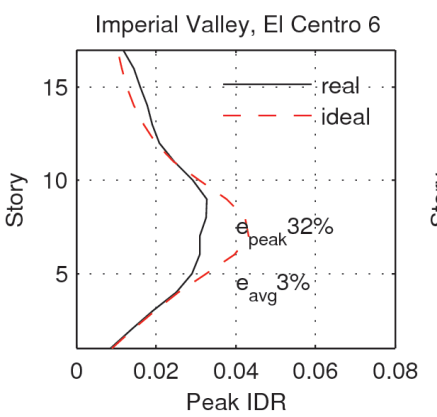

(c)

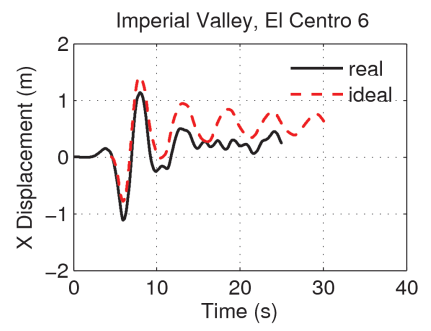

(g)

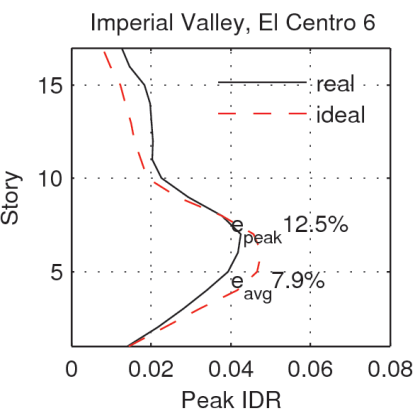

(d)

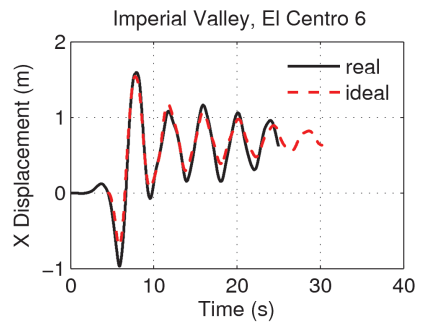

(h)

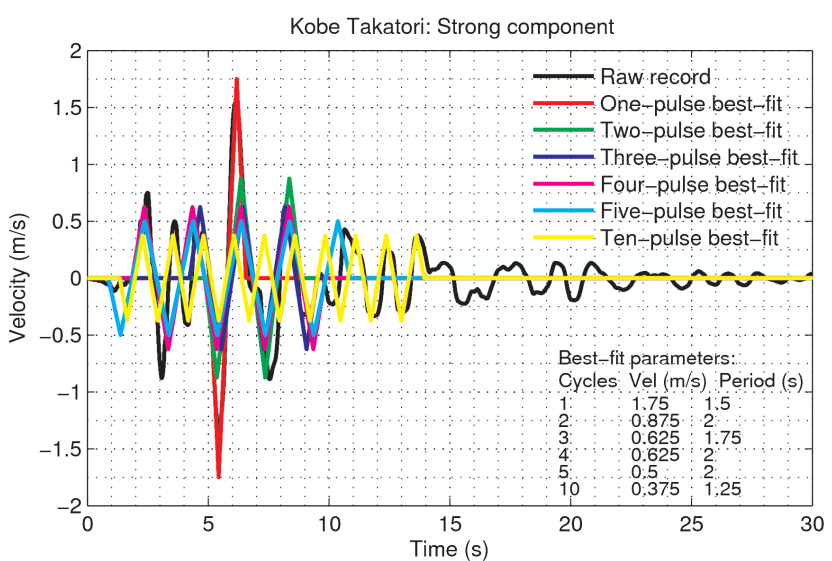

(b)

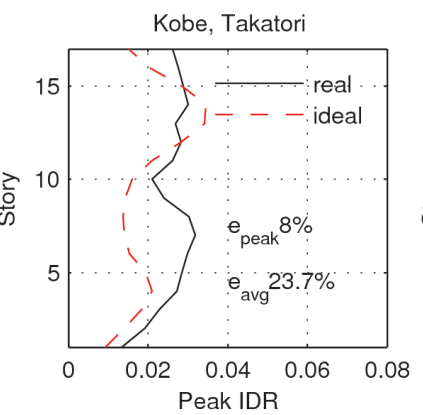

(e)

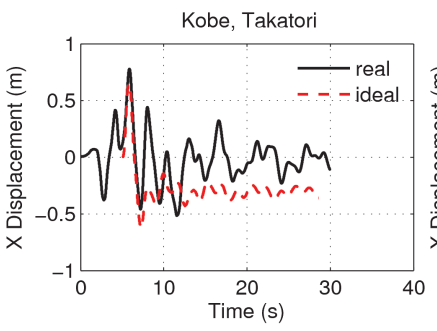

(i)

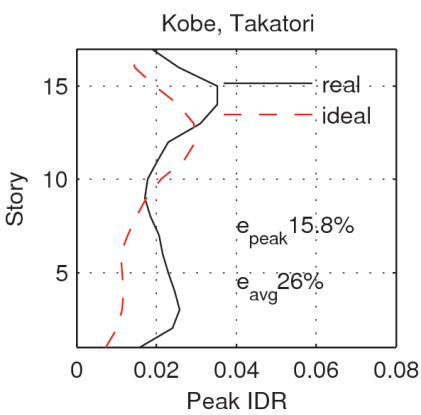

(f)

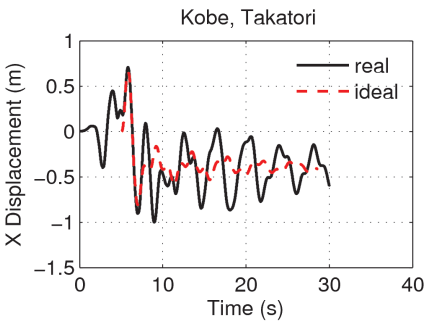

(j)

Figure 7: Near-source ground motion records from the (a) Imperial Valley and (b) Kobe earthquakes. Shown overlaid are the idealized 1-, 2-, 3-, 4-, 5-, and 10-cycle saw-tooth waveforms with the least absolute deviation ( $L_{1}$ norm) from the corresponding record. Also shown is the comparison of peak transient interstory drift ratio (IDR) profile over building height computed using real record against that computed using the best-fit idealized 1-cycle saw-tooth waveform for the (c) \& (e) existing building (susceptible connections); and (d) \& (f) the redesigned building (perfect connections). $e_{\text {peak }}$ and $e_{\text {avg }}$ are the maximum and average errors in the peak IDR, respectively, estimated using the idealized pulse motion. The corresponding comparisons of $18^{\text {th }}$ (Penthouse) floor X-direction displacement time-histories are shown in (g) \& (i) for the existing building, and (h) \& (j) for the redesigned building.

alized waveforms. Shown in Figure 7 is the comparison of the profiles of peak transient IDR over the height and penthouse response histories under the actual and idealized motions for the existing build- 
ing (susceptible connections) and the redesigned building (perfect connections) models for two ground motion cases. The degree of agreement in the IDR profiles and the penthouse response histories is fair enough to allow the use of the idealized waveforms as surrogates for earthquake excitation to establish the sensitivity of target building response to ground motion features. The peak values of IDR in all four building models from the two sets of analysis are compared against each other and the errors are quantified in Figure 8 (results from all 18 earthquake records are included). The mean and standard deviation of a Gaussian fit to the IDR errors are 0.00056 and 0.0069 , respectively. Both values are reasonably small. All 18 ground motion cases are included in this calculation.

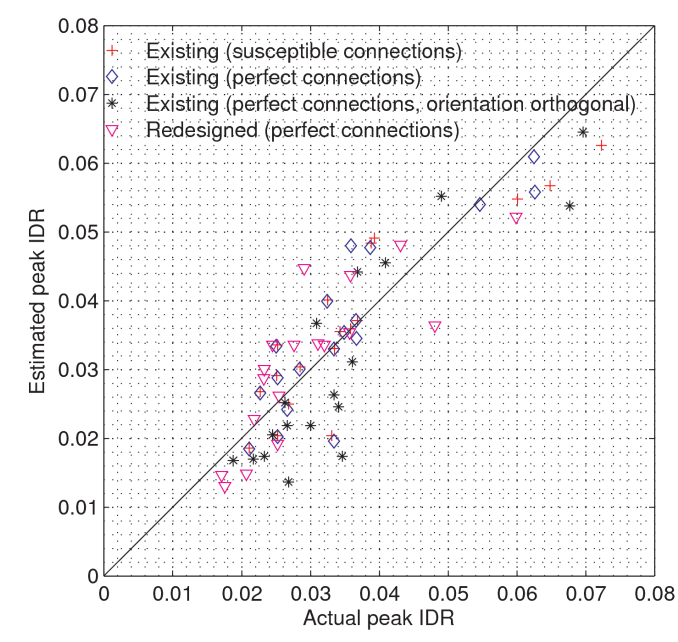

(a)

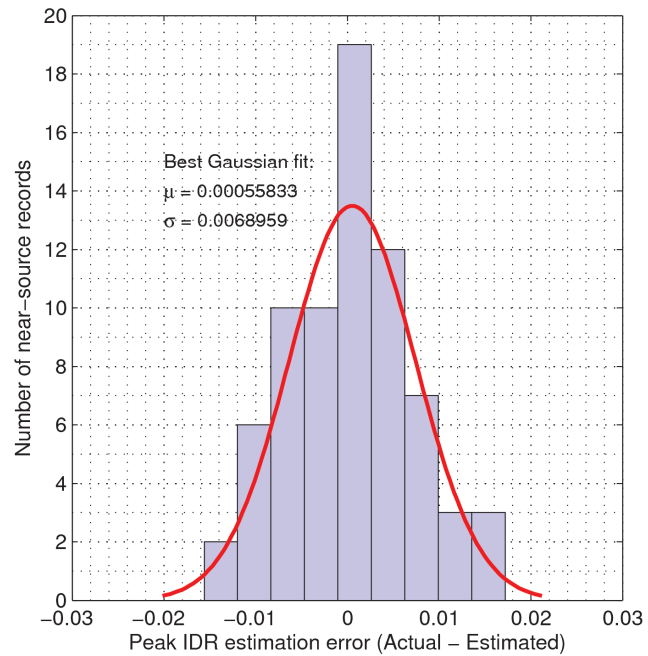

(b)

Figure 8: (a) Peak transient interstory drift ratio (IDR) in all the building models computed using the near-source records plotted against that computed using best-fit idealized 1-cycle saw-tooth waveforms. The diagonal line represents identical results from the two analyses. (b) Histogram of the error in determining the peak transient IDR from the idealized waveform as opposed to the actual record. The best-fit Gaussian is also shown.

\section{3.. Tall Building Response Sensitivity to Ground Motion Features}

To assess the sensitivity of structural response to ground motion features, a series of 3-D nonlinear response history analyses are conducted on the four building models: (a) Existing building (susceptible connections) under $\mathrm{X}$ direction excitation, (b) Existing building (perfect connections) under $\mathrm{X}$ 
direction excitation, (c) Existing building (perfect connections) under Y direction excitation, and (d) Redesigned building (perfect connections) under X direction excitation. The models are subjected to the idealized 1-component ground motion waveforms introduced in the last section with ground motion period $T$ varying between $0.5 \mathrm{~s}$ and $6.0 \mathrm{~s}$ at $0.25 \mathrm{~s}$ intervals, $P G V$ varying between $0.125 \mathrm{~m} / \mathrm{s}$ and $2.5 \mathrm{~m} / \mathrm{s}$ at $0.125 \mathrm{~m} / \mathrm{s}$ intervals, and the number of cycles $N$ taking the values of 1 to 5 and 10 . Key response metrics are computed and stored in a database. These include the peak transient inter-story drift ratio (IDR) and its location over the building height, the peak residual IDR and its location, permanent roof drift (or tilt) following seismic shaking, plastic rotations in beams, columns, and joints (panel zones), and locations of fractures in the model with fracture-susceptible connections. The peak residual IDR is computed by lowpass-filtering the interstory drift ratio histories and averaging the points within a 5 s time-window that has the lowest variance of all such time-windows in the record. A two-pass Butterworth filter with a corner at 10 s is employed ${ }^{3}$. A similar approach is adopted for computing the permanent roof drift which is the roof residual displacement normalized by building height. The penthouse is excluded from the peak transient IDR calculations.

In order to unravel the structural response sensitivity from all perspectives, the following maps and/or figures are generated for each building model and cataloged in a comprehensive report [22]: (i) color maps with contours of peak transient IDR (and its story location) on the $T-P G V$ plane, one map for each N; (ii) peak transient IDR (and its story location) maps on the $P G D-P G V$ plane, one map for each $N$; (iii) peak residual IDR (and its story location) maps on the $T$ - $P G V$ plane, one map for each $N$; (iv) peak residual IDR as a function of peak transient IDR, one map for each $N$; (v) permanent roof drift (roof residual displacement normalized by building height) maps on the $T$ - $P G V$ plane, one

\footnotetext{
${ }^{3}$ Despite padding the ground motion histories with $22 \mathrm{~s}$ of zeros, the structure does not come to a complete rest by the end of the record due to its low damping (2\%). However, the oscillations do settle down to small amplitudes about the permanent offset (residual displacement or interstory drift). The lowpass filter removes these oscillations and the average response value over the $5 \mathrm{~s}$ window with the lowest variance is a good approximation to the permanent offset.
} 


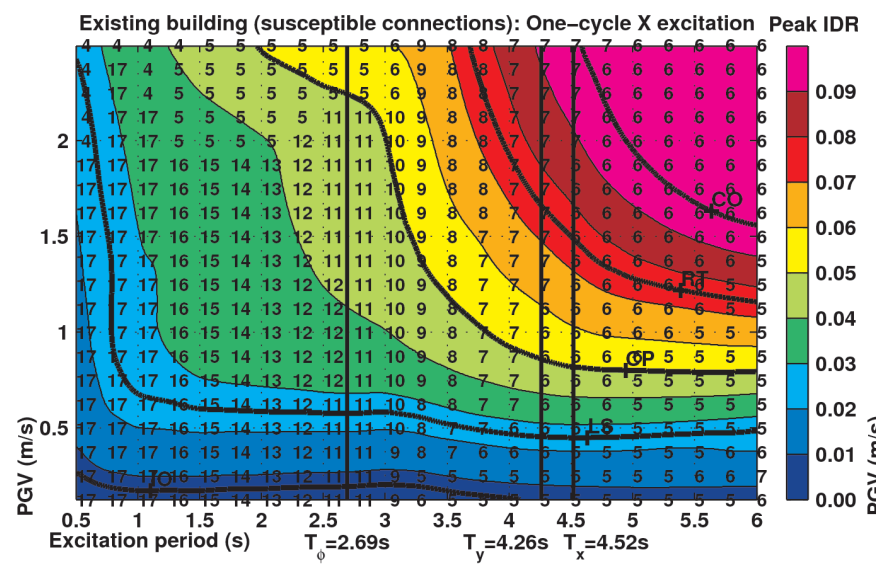

(a)

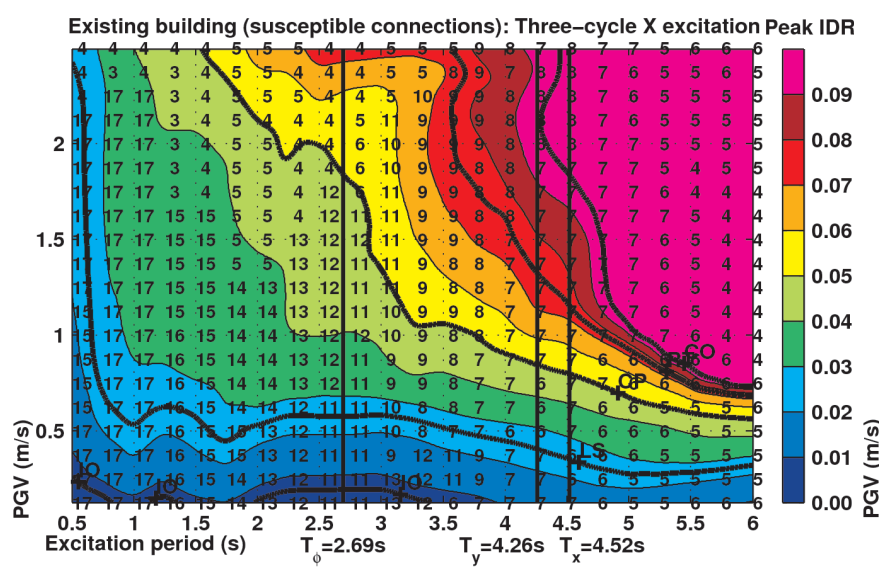

(c)

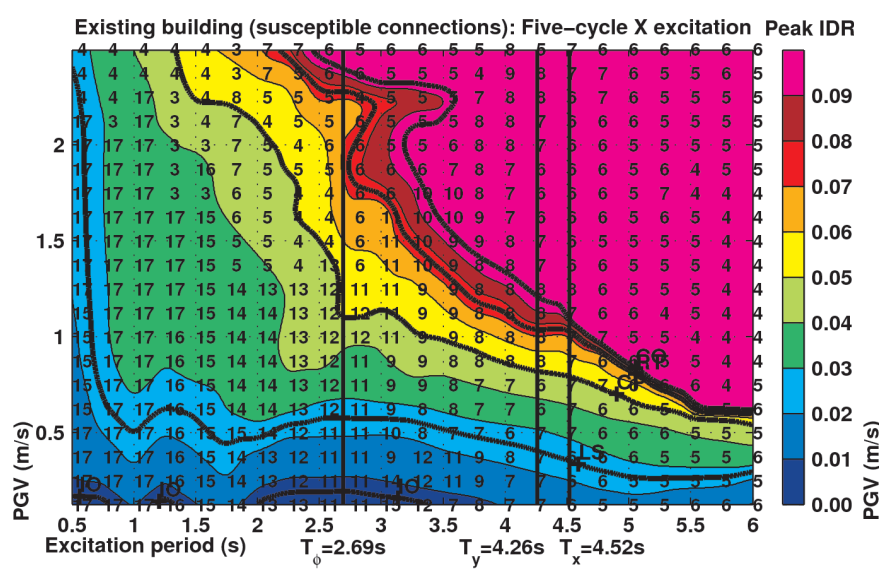

(e)

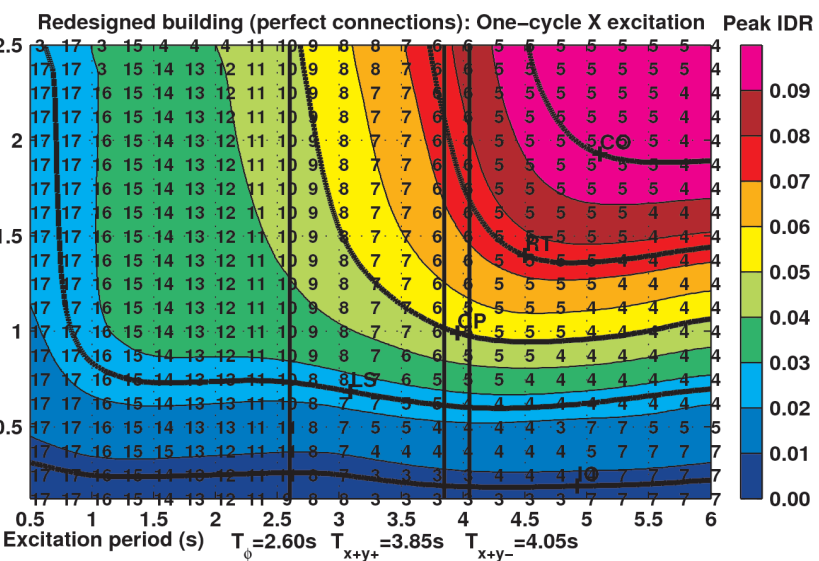

(b)

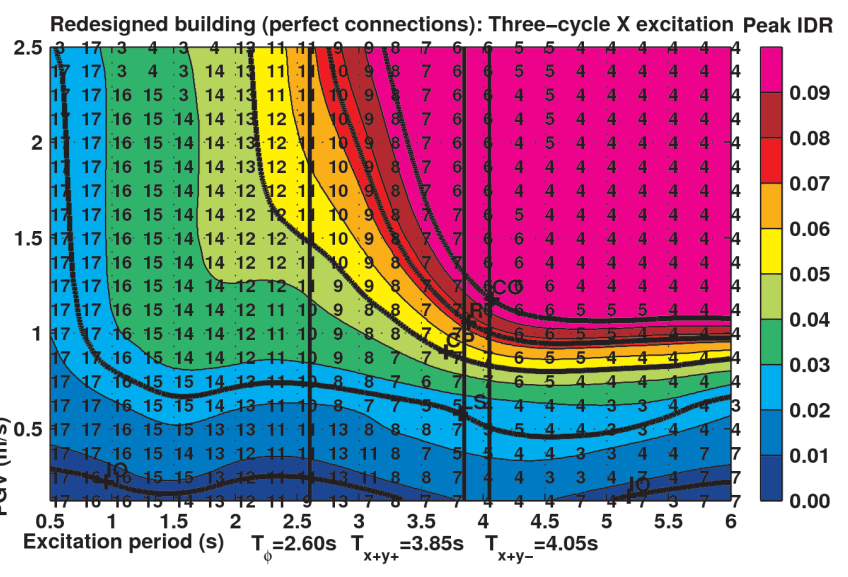

(d)

Redesigned building (perfect connections): Five-cycle $X$ excitation Peak IDR

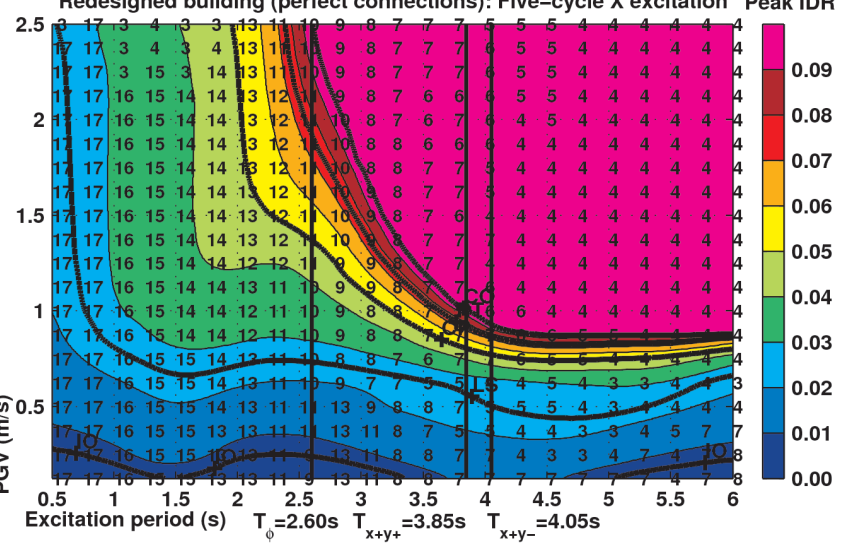

(f)

Figure 9: Peak transient interstory drift ratio (IDR) maps for the existing [susceptible connections, (a), (c), (e)] and the redesigned [perfect connections, (b), (d), (f)] buildings as a function of idealized saw-tooth waveform excitation parameters, period $T$, peak ground velocity $P G V$, and number of cycles $N$. The one-component ground motion is applied in the building $\mathrm{X}$ direction. The story location where the peak occurs is labeled at each of the $460[T, P G V]$ combinations for which analyses were performed. Contours corresponding to empirical performance levels of immediate occupancy (IO), life-safety (LS), collapse prevention (CP), red-tagged (RT), and collapsed $(\mathrm{CO})$, are shown in bold font. The principal direction building fundamental periods are indicated for reference. 
map for each $N$; (vi) permanent roof drift as a function of peak transient IDR, one map for each $N$; (vii) curves of peak transient IDR (with story locations) as a function of $T$, one curve for each $P G V$ and $N$; (viii) curves of peak transient IDR (with story locations) as a function of $P G V$, one curve for each $T$ and $N$; and (ix) curves of peak transient IDR (with story locations) as a function of $N$, one curve for each $T$ and $P G V$.

For the contour maps, the data from the coarse parametric analysis grid are interpolated on to a fine parameter grid using Delaunay triangulation with linear interpolation [42]. A volume-preserving circular-averaging correlation filter ${ }^{4}$ is subsequently applied to the data in order to smoothen sharp transitions in the contours. Also plotted on the peak transient IDR maps are contours corresponding to upper limits on IDR for Immediate Occupancy (IO; IDR=0.007), Life Safety (LS; IDR=0.025), and Collapse Prevention (CP; IDR=0.05) performance levels [6]. In addition, contours corresponding to peak transient IDRs of 0.075 and 0.100 are also shown. In thousands of collapse analyses conducted by the authors on models such as the ones considered in this study, gravity-driven progressive collapse takes hold of a large percentage our numerical models beyond peak transient IDRs of 0.100 . Given that the models do not include certain critical failure modes such as local buckling in column flanges, peak transient IDRs greater than 0.10 in the physical structure would almost surely result in complete collapse. The peak transient IDR range of 0.075-0.100 (CO) may be indicative of partial to complete collapse (unstable). Models with intermediate peak transient IDRs in the range of 0.050-0.075 can be expected to be on the verge of collapse (neutrally stable) and hence may be red-tagged (RT).

The following observations can be made from the results of the simulations:

\footnotetext{
${ }^{4}$ Correlation and convolution filtering are standard digital signal processing techniques to filter a signal in time or space. An image can be blurred, for example, by assigning each pixel a value equal to the average of that pixel and its four neighbors. This can be mathematically accomplished by either convolution or correlation of the pixel data with a unit-volume filter or kernel. Convolution involves space-reversing the filter (rotating the kernel by $180^{\circ}$ ), translating it over the data, and summing the overlap (integrating the product of the time-reversed volume-preserving filter and the data). Correlation involves the same process, except that the integration is performed without space-reversing the filter.
} 
(a) Figure 9 shows the peak transient IDR maps on the $T-P G V$ plane for the existing building model with susceptible connections under 1-, 3-, and 5-cycle, X direction idealized waveform excitation. Figure 10 shows the corresponding maps, but on the $P G V-P G D$ plane, for the redesigned building model with perfect connections under 3-cycle, $\mathrm{X}$ direction excitation. In the frequency and amplitude bands of relevance to seismic ground motion, the peak transient IDR response is more or less monotonously increasing (or constant, but not decreasing) with increasing $P G V$ at a given $T$ level. The same is more or less true with increasing $T$ at a given $P G V$ level. This desirable feature in as far as identifying damaging features of ground motion is concerned is not necessarily true at given levels of peak ground displacement $(P G D)$. For example, for two 3-cycle ground motion records with $P G D=1.5 \mathrm{~m}$, the peak transient IDR in the existing building with susceptible connections [Figure 10(a)] points to collapse under the record with $P G V=1.25 \mathrm{~m} / \mathrm{s}$, but only red-tagged under the record with $P G V=2.25 \mathrm{~m} / \mathrm{s}$. This suggests that structural response can be more simply characterized using the $P G V-T$ combination rather than the $P G V-P G D$ combination.

(b) The IO and LS regimes (peak transient IDR < 0.025) do not shrink significantly with increasing number of ground motion cycles (see Figure 9). Plasticity levels, if at all yielding occurs, are quite low at these low IDRs. This can be clearly seen in Figure 11 where the peak residual IDR is shown plotted against the peak transient IDR in the existing building model with susceptible connections, when subjected to 1- and 3-cycle X direction excitation. Residual (permanent) IDR is insignificant when transient IDR $<0.025$. As a result, not much degradation is expected due to increased number of cycles. This holds true even for the existing building model with connections susceptible to fracture, perhaps because the susceptibility to fracture exists only in beams and not in columns of the model. Moreover, this susceptibility is quite low in the beam top flange and web. Another factor may be that low-cycle fatigue is not considered in the modeling approach. There is some, although 


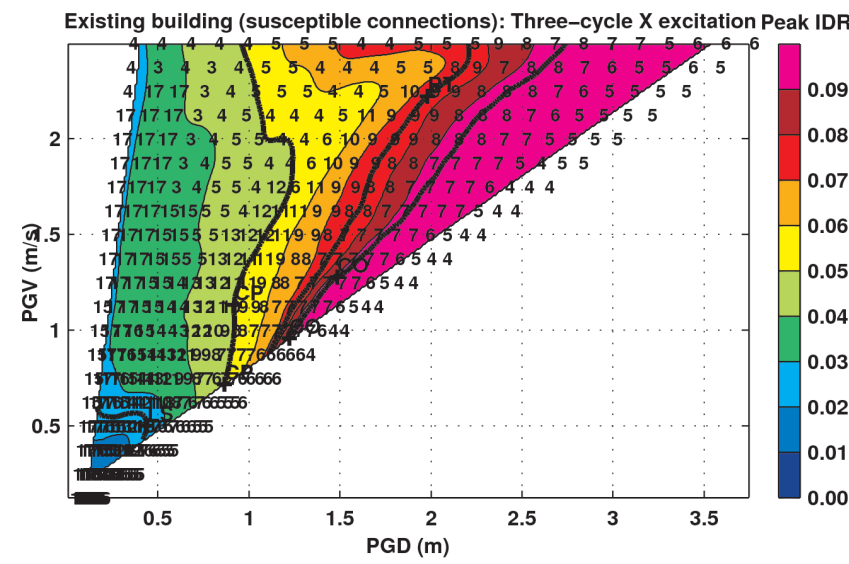

(a)

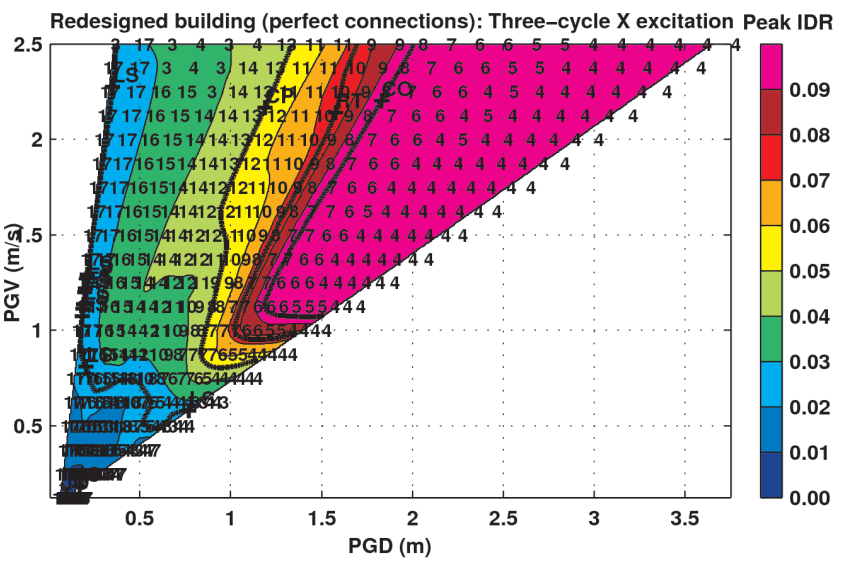

(b)

Figure 10: Peak transient interstory drift ratio (IDR) maps for the existing [susceptible connections, (a)] and the redesigned [perfect connections, (b)] buildings as a function of the peak ground displacement $(P G D)$ and peak ground velocity $(P G V)$ under idealized 3-cycle saw-tooth waveform excitation. The one-component ground motion is applied in the building $\mathrm{X}$ direction. The story location where the peak occurs is labeled at each of the $460[T, P G V]$ combinations for which analyses were performed. Contours corresponding to empirical performance levels of immediate occupancy (IO), life-safety (LS), collapse prevention (CP), redtagged (RT), and collapsed (CO), are shown in bold font.

only mildly significant, shrinking in the $\mathrm{CP}$ regime with increasing number of cycles. The greatest change going from 1-cycle to 10-cycle excitation is the dramatic and progressive expansion of the collapse regime at the expense of the shrinking of the $\mathrm{CP}-\mathrm{CO}$ regime. In other words, under multicycle excitation $(N>2)$, there is a steep gradient in the response surface going from collapse-safe performance to complete global collapse with small increases in the ground motion period and/or peak ground velocity. This is especially true in the long-period excitation regime $\left(T>T_{1}\right.$, where $T_{1}$ is the fundamental natural period of the building), where there is little difference in $P G V$ thresholds for $\mathrm{CP}, \mathrm{RT}$, and $\mathrm{CO}$ performance levels. This points to the extreme sensitivity of structural response to the velocity amplitude of long-period, long-duration ground motion. Performance can range from satisfactory to complete collapse with subtle differences in the $P G V$ in the vicinity of the $\mathrm{CP} / \mathrm{RT} / \mathrm{CO}$ thresholds. This swift degradation of strength with increasing number of cycles is similar to the postyield deterioration of strength observed under monotonic quasi-static pushover loading (Figure 5). 


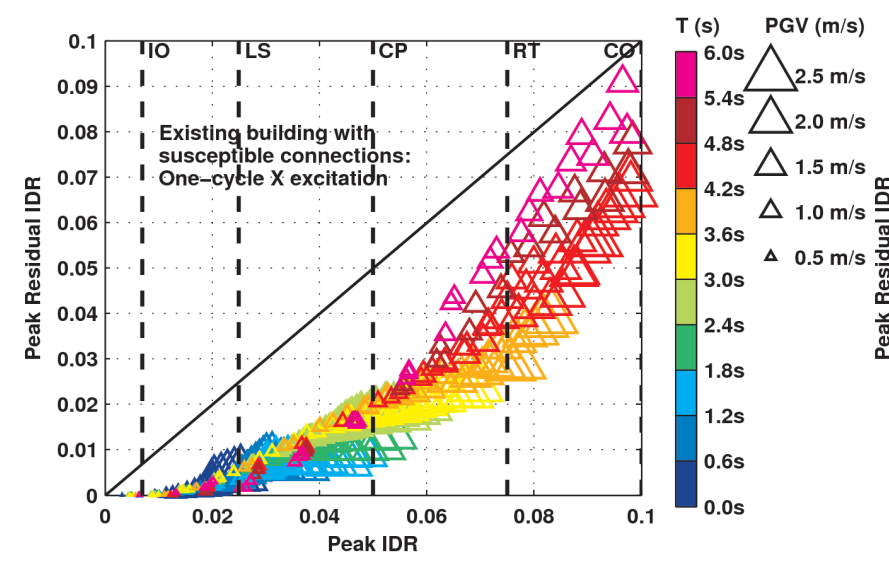

(a)

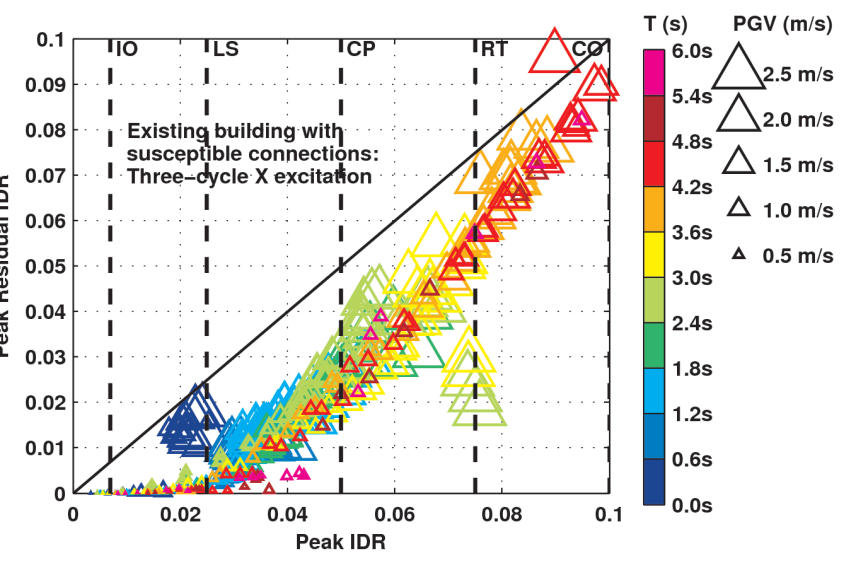

(b)

Figure 11: Peak residual interstory drift ratio (RIDR) in the existing building (susceptible connections) plotted as a function of the peak transient IDR under idealized saw-tooth waveform excitation. The results for (a) 1-cycle and (b) 3-cycle excitations are shown separately. The one-component ground motion is applied in the building $\mathrm{X}$ direction. Points corresponding to peak transient IDR $>0.10$ are indicative of near-certain collapse; residual IDR is no longer meaningful. Hence, these points are not shown. The immediate occupancy (IO), life-safety (LS), collapse prevention (CP), red-tagged (RT), and collapsed (CO) performance levels are marked on the IDR axis.

The threshold values for the exceedance of the CP, RT, and CO performance levels of (a) idealized wave period at $P G V$ of $2.5 \mathrm{~m} / \mathrm{s}$ and (b) $P G V$ at period of $6 \mathrm{~s}$, for various number of idealized wave cycles, are listed in Table 1 for all four building models ${ }^{5}$.

(c) For near-certain complete collapse (peak transient IDR $>0.10$ ) of buildings with perfect connections to occur under 1- or 2-cycle excitation (e.g., near-source records), the excitation period must exceed roughly the building fundamental period. For the existing building, the excitation period must exceed $4.5 \mathrm{~s}$, whereas, for the redesigned building, it must exceed 4.0s (see Figures 12(a) and 12(b)). However, the $P G V$ threshold for collapse of the redesigned building under 2-cycle excitation is higher $(1.2 \mathrm{~m} / \mathrm{s}$ from Figure $12(\mathrm{~d}))$ than that of the existing building $(0.9 \mathrm{~m} / \mathrm{s}$ from Figure $12(\mathrm{c}))$. Furthermore, this intensity threshold holds steady for cycles with a wide range of periods (4s-6s)

\footnotetext{
${ }^{5}$ It should be pointed out that a $P G V$ of, say, $1 \mathrm{~m} / \mathrm{s}$ at $T=6 \mathrm{~s}$ period is indicative of a seismic waveform with far greater energy than one with $P G V$ of $1 \mathrm{~m} / \mathrm{s}$ at $T=1 \mathrm{~s}$ period. These waveforms could result from vastly different seismic sources in significantly distinct geological settings. Due consideration must be given to these aspects when making any direct comparisons.
} 


\begin{tabular}{|c|c|c|c|c|c|c|c|}
\hline \multirow[t]{2}{*}{ Model } & \multirow[t]{2}{*}{$N$} & \multicolumn{2}{|c|}{ Thresholds for CP } & \multicolumn{2}{|c|}{ Thresholds for RT } & \multicolumn{2}{|c|}{ Thresholds for CO } \\
\hline & & $\begin{array}{c}P G V(\mathrm{~m} / \mathrm{s}) \\
@ T=6 \mathrm{~s}\end{array}$ & $\begin{array}{c}T(\mathrm{~s}) \\
@ P G V=2.5 \mathrm{~m} / \mathrm{s}\end{array}$ & $\begin{array}{c}P G V(\mathrm{~m} / \mathrm{s}) \\
@ T=6 \mathrm{~s}\end{array}$ & $\begin{array}{c}T(\mathrm{~s}) \\
@ P G V=2.5 \mathrm{~m} / \mathrm{s}\end{array}$ & $\begin{array}{c}P G V(\mathrm{~m} / \mathrm{s}) \\
@ T=6 \mathrm{~s}\end{array}$ & $\begin{array}{c}T(\mathrm{~s}) \\
@ P G V=2.5 \mathrm{~m} / \mathrm{s}\end{array}$ \\
\hline $\begin{array}{c}\text { Existing } \\
\text { building } \\
\text { (susceptible } \\
\text { connections) } \\
\text { X direction } \\
\text { excitation }\end{array}$ & $\begin{array}{c}1 \\
2 \\
3 \\
4 \\
5 \\
10\end{array}$ & $\begin{array}{l}0.800 \\
0.625 \\
0.600 \\
0.600 \\
0.600 \\
0.500\end{array}$ & $\begin{array}{l}2.00 \\
1.75 \\
1.50 \\
1.40 \\
1.25 \\
1.00\end{array}$ & $\begin{array}{l}1.150 \\
0.750 \\
0.700 \\
0.625 \\
0.600 \\
0.500\end{array}$ & $\begin{array}{l}3.60 \\
3.60 \\
3.50 \\
2.35 \\
2.20 \\
1.35\end{array}$ & $\begin{array}{l}1.575 \\
0.900 \\
0.750 \\
0.625 \\
0.625 \\
0.500\end{array}$ & $\begin{array}{l}4.50 \\
4.50 \\
4.45 \\
4.00 \\
2.50 \\
1.50\end{array}$ \\
\hline $\begin{array}{c}\text { Existing } \\
\text { building } \\
\text { (perfect } \\
\text { connections) } \\
\text { X direction } \\
\text { excitation }\end{array}$ & $\begin{array}{c}1 \\
2 \\
3 \\
4 \\
5 \\
10\end{array}$ & $\begin{array}{l}0.810 \\
0.750 \\
0.690 \\
0.625 \\
0.600 \\
0.500\end{array}$ & $\begin{array}{l}2.10 \\
2.10 \\
2.10 \\
2.10 \\
2.10 \\
1.30\end{array}$ & $\begin{array}{l}1.250 \\
0.875 \\
0.800 \\
0.720 \\
0.650 \\
0.500\end{array}$ & $\begin{array}{l}4.50 \\
4.50 \\
4.25 \\
4.00 \\
3.75 \\
1.60\end{array}$ & $\begin{array}{l}1.900 \\
1.125 \\
0.875 \\
0.775 \\
0.720 \\
0.500\end{array}$ & $\begin{array}{l}5.63 \\
5.10 \\
4.75 \\
4.50 \\
4.25 \\
1.80\end{array}$ \\
\hline $\begin{array}{c}\text { Existing } \\
\text { building } \\
\text { (perfect } \\
\text { connections) } \\
\text { Y direction } \\
\text { excitation }\end{array}$ & $\begin{array}{c}1 \\
2 \\
3 \\
4 \\
5 \\
10\end{array}$ & $\begin{array}{l}0.860 \\
0.740 \\
0.650 \\
0.625 \\
0.600 \\
0.500\end{array}$ & $\begin{array}{l}1.90 \\
1.90 \\
1.90 \\
1.80 \\
1.60 \\
1.25\end{array}$ & $\begin{array}{l}1.180 \\
0.875 \\
0.750 \\
0.700 \\
0.625 \\
0.500\end{array}$ & $\begin{array}{l}4.50 \\
4.45 \\
4.30 \\
3.50 \\
2.30 \\
1.40\end{array}$ & $\begin{array}{l}1.650 \\
1.025 \\
0.850 \\
0.725 \\
0.625 \\
0.500\end{array}$ & $\begin{array}{l}5.40 \\
4.80 \\
4.50 \\
4.25 \\
3.40 \\
1.50\end{array}$ \\
\hline $\begin{array}{l}\text { Redesigned } \\
\text { building } \\
\text { (perfect } \\
\text { connections) } \\
\text { X direction } \\
\text { excitation }\end{array}$ & $\begin{array}{c}1 \\
2 \\
3 \\
4 \\
5 \\
10\end{array}$ & $\begin{array}{l}1.100 \\
0.950 \\
0.875 \\
0.850 \\
0.825 \\
0.750\end{array}$ & $\begin{array}{l}2.65 \\
2.20 \\
2.10 \\
2.05 \\
2.00 \\
1.75\end{array}$ & $\begin{array}{l}1.450 \\
1.130 \\
1.000 \\
0.900 \\
0.875 \\
0.800\end{array}$ & $\begin{array}{l}3.70 \\
3.15 \\
2.75 \\
2.50 \\
2.40 \\
2.05\end{array}$ & $\begin{array}{l}1.900 \\
1.350 \\
1.100 \\
0.975 \\
0.875 \\
0.800\end{array}$ & $\begin{array}{l}4.50 \\
3.70 \\
3.20 \\
2.80 \\
2.60 \\
2.08\end{array}$ \\
\hline
\end{tabular}

Table 1: Peak ground velocity and period thresholds for the exceedance of the collapse prevention (CP), redtagged (RT), and collapsed (CO) performance levels for all building models. $N$ is the number of cycles of ground excitation.

in the case of the redesigned building. It does not drop with increasing period as in the case of the existing building.

(d) The $P G V$ thresholds for near-certain complete collapse (peak IDR $>0.10$ ) under 1-cycle to 10-cycle $\mathrm{X}$ direction excitation varies approximately from $1.575 \mathrm{~m} / \mathrm{s}$ to $0.5 \mathrm{~m} / \mathrm{s}$ for the existing building model with susceptible connections, from $1.9 \mathrm{~m} / \mathrm{s}$ to $0.5 \mathrm{~m} / \mathrm{s}$ for the existing building model with perfect 


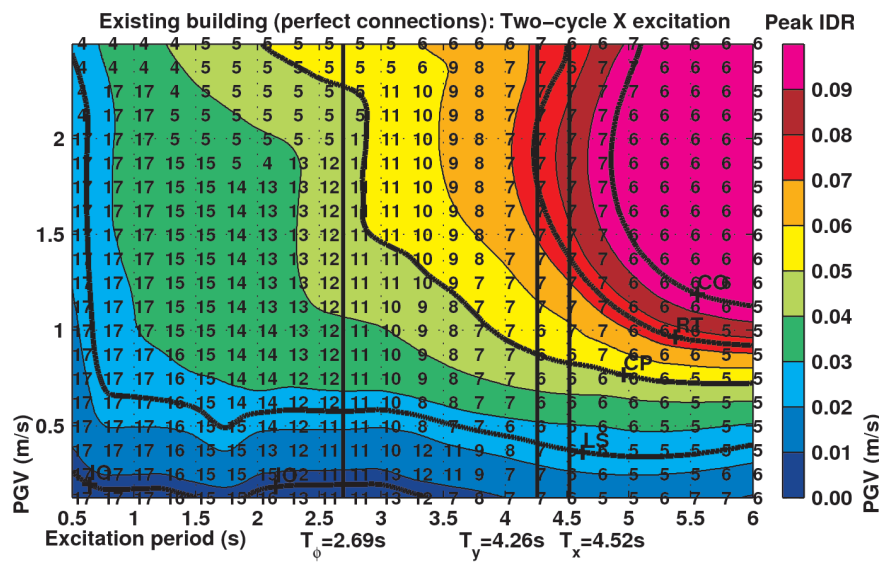

(a)

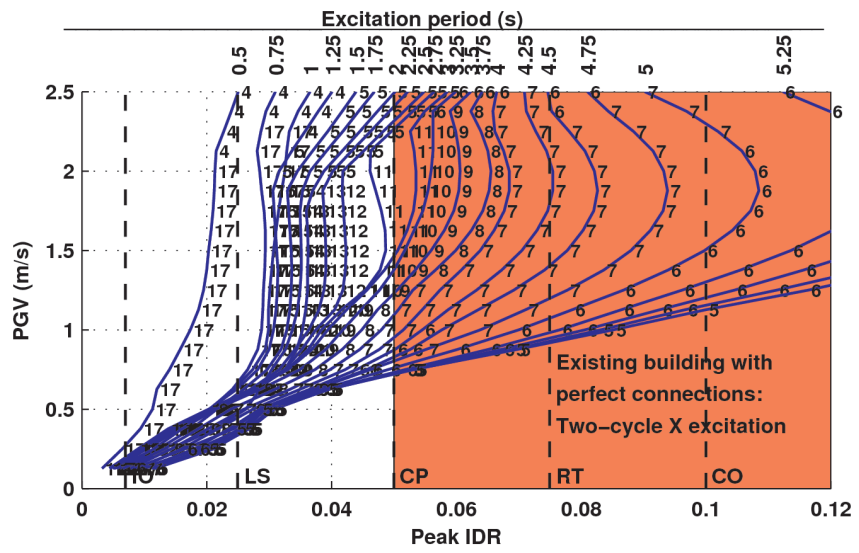

(c)

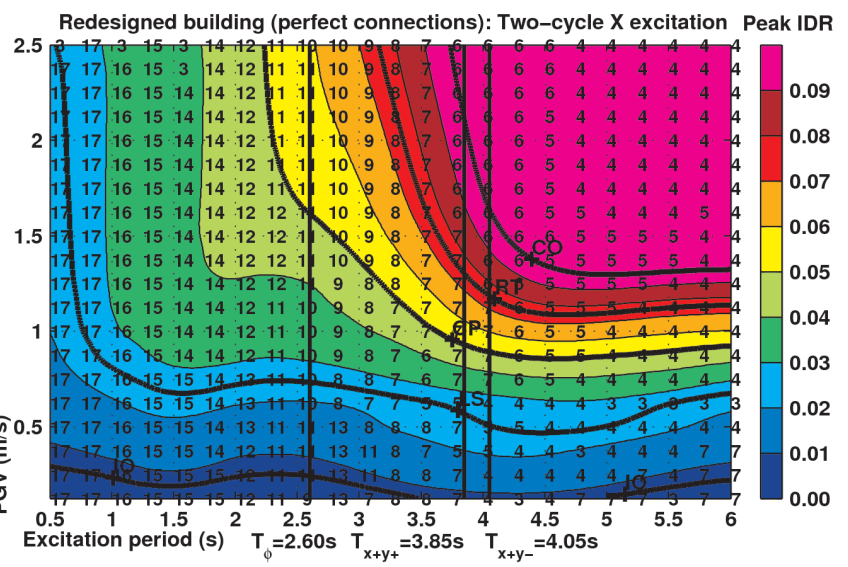

(b)

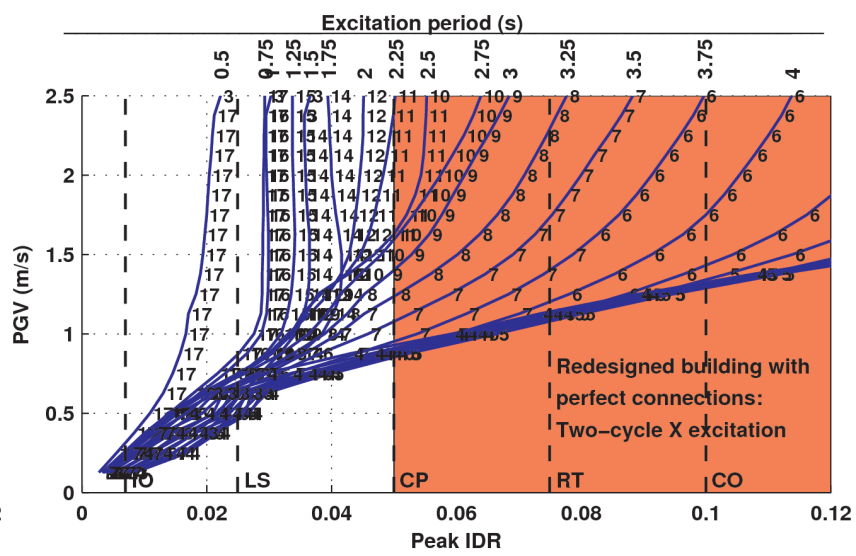

(d)

Figure 12: Peak transient interstory drift ratio (IDR) maps on the $T-P G V$ plane, and peak transient IDR versus peak ground velocity $P G V$ curves at various excitation periods $T$, for the existing building [perfect connections, (a), (c)] and the redesigned building [perfect connections, (b), (d)] under 2-cycle idealized sawtooth waveform excitation. The one-component ground motion is applied in the building $\mathrm{X}$ direction. The story location where the peak occurs is labeled at each of the $460[T, P G V]$ combinations for which analyses were performed. Contours corresponding to the empirical IO, LS, CP, RT, and CO performance levels are shown in bold font. The principal direction building fundamental periods are indicated for reference.

connections, and from $1.9 \mathrm{~m} / \mathrm{s}$ to $0.8 \mathrm{~m} / \mathrm{s}$ for the redesigned building model with perfect connections

(Table 1). These values apply to long-period ground motion $(T=6 s)$. There is a big drop in the

$P G V$ thresholds from 1-cycle excitation to 2-cycle excitation. Beyond 2 cycles, the drop in the

$P G V$ thresholds is more gradual with increasing number of cycles.

(e) Collapse risk is negligible/minor if ground motion $P G V<0.5 \mathrm{~m} / \mathrm{s}$ or $T<1.5 \mathrm{~s}$ for $N \leq 5$ for all 


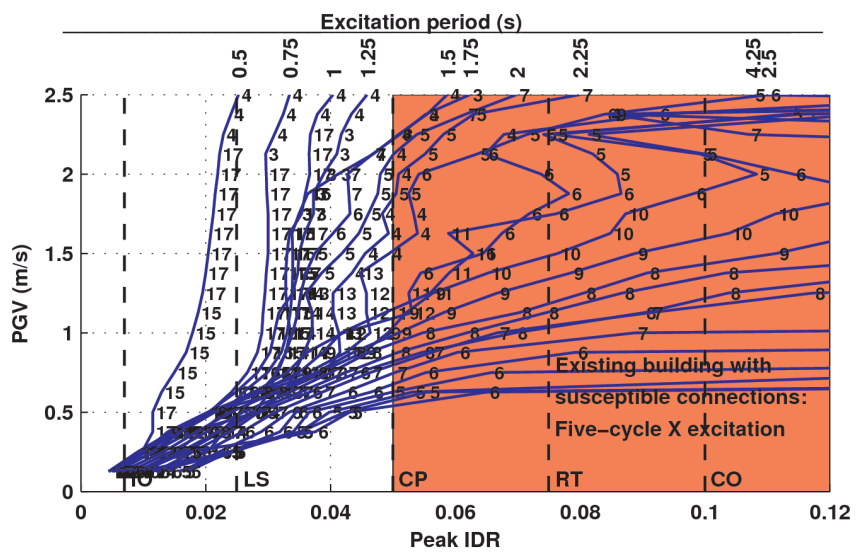

(a)

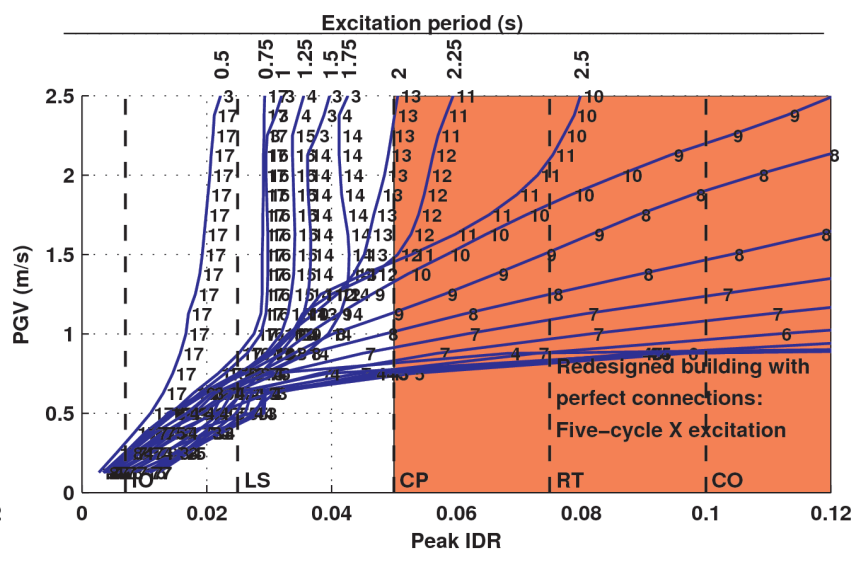

(b)

Figure 13: Peak transient interstory drift ratio (IDR) is shown plotted against the idealized 5-cycle, saw-tooth waveform excitation peak ground velocity $(P G V)$ for (a) the existing (susceptible connections) and (b) the redesigned (perfect connections) buildings at various levels of waveform periods $(T)$. The one-component ground motion is applied in the building $\mathrm{X}$ direction. The story location where the peak occurs is labeled at each of the $460[T, P G V]$ combinations for which analyses were performed. The empirical immediate occupancy (IO), life-safety (LS), collapse prevention (CP), red-tagged (RT), and collapsed (CO) performance levels are marked on the IDR axis.

four building models (e.g., see Figure 13).

(f) Partial (and perhaps complete) collapse (peak transient IDR $>0.075$ ) is almost certain to occur in all four models if ground excitation has a period $T>5 \mathrm{~s}$, a velocity amplitude $P G V>1 \mathrm{~m} / \mathrm{s}$, and has more than one cycle $(N>1)$.

(g) While the areal coverage on the $P G V-T$ plane of the "CP or worse" regime is about the same in both the existing and redesigned building models (both with perfect connections), the significantly higher $P G V$ threshold for collapse of the redesigned building under long period ground motion $(T>5 s)$ is the main benefit of the 1997 UBC design when compared to the 1982 UBC design. In addition, the $P G V$ threshold for Life-Safe (LS) performance holds steady for the redesigned building model with increasing $\mathrm{T}$, whereas it drops rapidly for the existing building model with increasing T. The stiffer, but stronger, redesigned building is thus more robust in its response to long period ground motion when compared against the more flexible, but weaker, existing building model. The 
same is generally true for high $P G V$-low $T$ excitation as well with the redesigned building model outperforming the existing building model. However, in the intermediate period range $(T=3-4 s)$, the performance of the redesigned building is distinctly worse than that of the existing building, but only when the $P G V$ exceeds about $1 \mathrm{~m} / \mathrm{s}$. This is a direct consequence of the shift in the dynamic characteristics of the redesigned building toward the higher frequencies. Thus, the stiffening that typically accompanies strengthening results in a tradeoff in system performance, greater robustness to short and long period motions going hand-in-hand with marginally poorer performance under intermediate period excitations, for the building considered in this study.

(h) The effect of connection susceptibility to fracture in lowering the $P G V$ threshold for collapse under long period ground excitation $(T>5 s)$ is clear. This effect diminishes with increasing number of cycles as the degradation due to fracture saturates after a few cycles, while degradation due to plasticity continues to grow with increasing number of cycles. Ultimately, under 10-cycle excitation, both the perfect and susceptible connection models have similar $P G V$ thresholds for collapse under the $T=6 s$ ground motion (within approximately $0.125 \mathrm{~m} / \mathrm{s}$ of each other which is the PGV discretization size for the parametric analysis conducted here). However, for shorter period ground motion $(T=3 s)$ the $P G V$ threshold for collapse under 10 -cycle ground motion is far greater $(1.75 \mathrm{~m} / \mathrm{s}$ from Figure 14(a)) for the perfect connection model than for the susceptible connection model $(1.15 \mathrm{~m} / \mathrm{s}$ from Figure 14(b)). As a result, the areal coverage of the collapse regime in the $T-P G V$ plane is much greater for the fracture susceptible connection model when compared against the perfect connection model.

(i) Peak residual IDR occurs only beyond the LS performance level (peak transient IDR of 0.025) and grows linearly, but slowly until the $\mathrm{CP}$ performance level, then accelerates significantly. Beyond this level of performance, much of the transient IDR is not recovered and residual IDR forms a much 


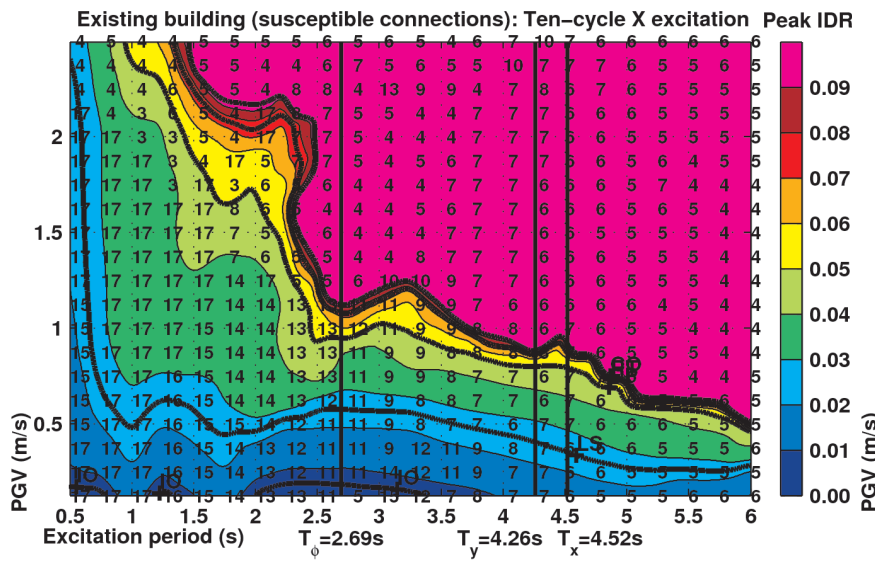

(a)

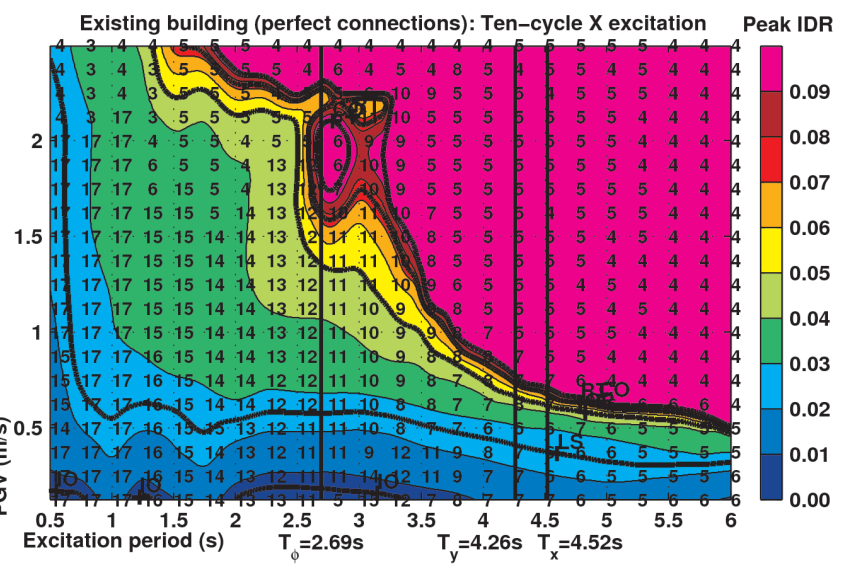

(b)

Figure 14: Peak transient interstory drift ratio (IDR) maps for (a) the fracture-susceptible and (b) the perfect connection models of the existing building as a function of excitation period $T$ and peak ground velocity $P G V$, for 10-cycle idealized saw-tooth waveform excitation. The one-component ground motion is applied in the building $\mathrm{X}$ direction. The story location where the peak occurs is labeled at each of the $460[T, P G V]$ combinations for which analyses were performed. Contours corresponding to empirical performance levels of immediate occupancy (IO), life-safety (LS), collapse prevention (CP), red-tagged (RT), and collapsed (CO), are shown in bold font. The principal direction building fundamental periods are indicated for reference.

greater percentage of the transient IDR (e.g., see Figure 11). Iwata et al. [13] conducted a study of twelve steel structures damaged in the 1995 Kobe earthquake. Using the measured peak residual IDR and reported repair costs, they estimated a reparability limit of 0.015 for the peak residual IDR. However, there are two cases presented by them where buildings with peak residual IDR greater than 0.02 were successfully repaired. In most cases, this level of peak residual IDR is reached when the peak transient IDR exceeds 0.05 , the CP performance level. Thus, while the structure may not have collapsed at this IDR level, it certainly becomes unusable at this stage. This lends credence to the red-tagging of these buildings beyond the peak transient IDR of 0.05 that is adopted in this study.

(j) There is a high degree of correlation between the permanent roof drift (roof residual displacement normalized by building height) and the peak residual IDR as evidenced by the close correspondence between their relationships to the peak transient IDR (compare Figures 15 and 11). So the amount of lean (or tilt) following an earthquake could perhaps be used to estimate the peak residual IDR and 


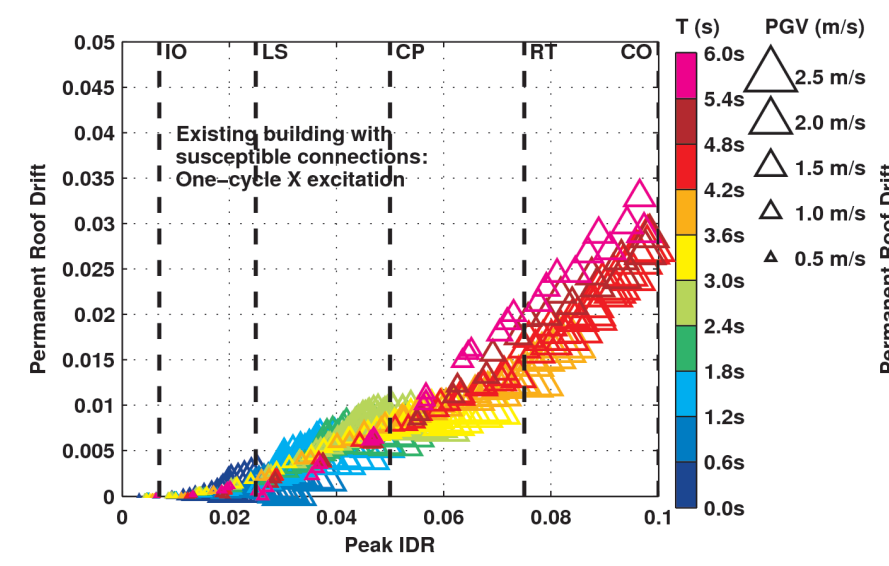

(a)

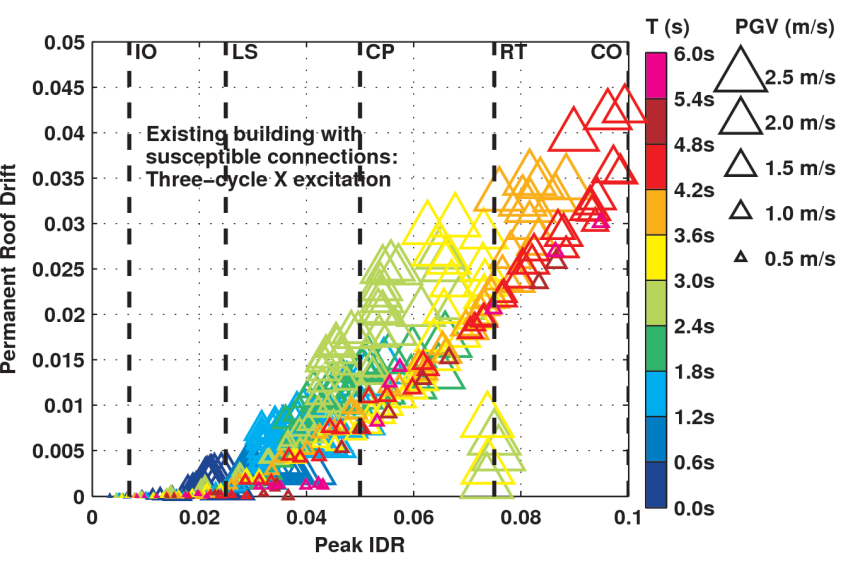

(b)

Figure 15: Permanent roof drift (tilt normalized by height) in the existing building (susceptible connections) plotted as a function of the peak transient interstory drift ratio (IDR) under idealized saw-tooth waveform excitation. The results for (a) 1-cycle and (b) 3-cycle excitations are shown separately. The one-component ground motion is applied in the building $\mathrm{X}$ direction. Points corresponding to peak transient IDR $>0.10$ are indicative of near-certain collapse; residual IDR is no longer meaningful. Hence, these points are not shown. The empirical immediate occupancy (IO), life-safety (LS), collapse prevention (CP), red-tagged (RT), and collapsed (CO) performance levels are marked on the IDR axis.

hence the post-earthquake condition of the building [13].

(k) The number of cycles of ground excitation has minimal impact in cases where peak transient IDR is below the $\mathrm{CP}$ limit. If the peak transient IDR exceeds the $\mathrm{CP}$ limit, degradation is swift with increasing number of cycles for both susceptible-connection as well as perfect-connection building models (Figure 16), once again reminiscent of the post-yield strength degradation observed under monotonic quasi-static pushover loading (Figure 5).

(1) The story location of peak transient IDR closely tracks the ground excitation period $T$, steadily dropping from the top of the building with increasing $T$. The downward migration halts not at the bottom story, but slightly higher. This phenomenon has important implications for the mechanism of collapse of these building models [22, 23].

(m) Under short period excitation $(T<1.5 s)$. the peak transient IDR saturates to a value below the CP limit with increasing $P G V$ (e.g., Figure 13). Under longer period ground motion, the peak 


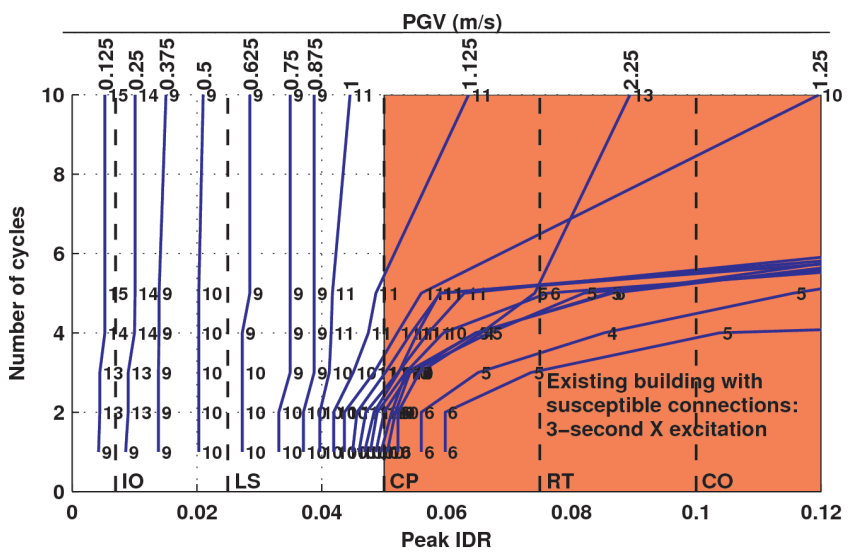

(a)

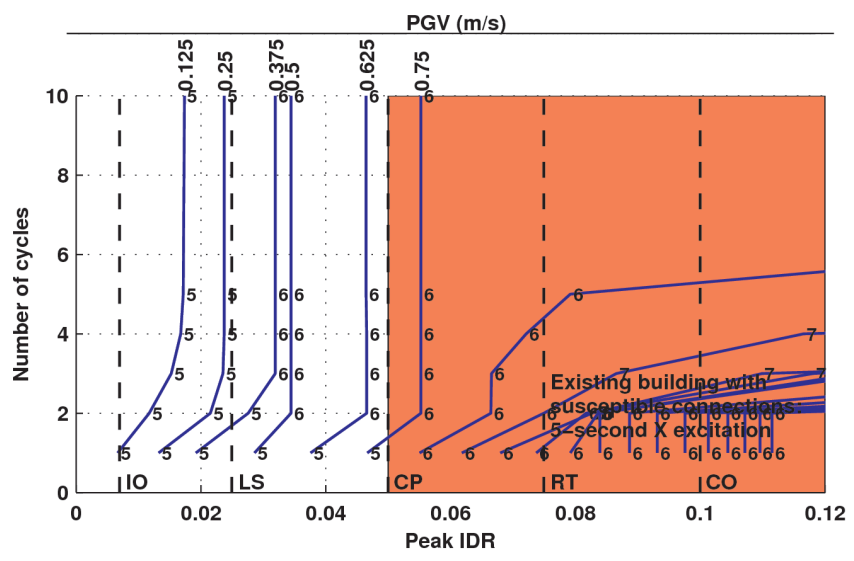

(c)

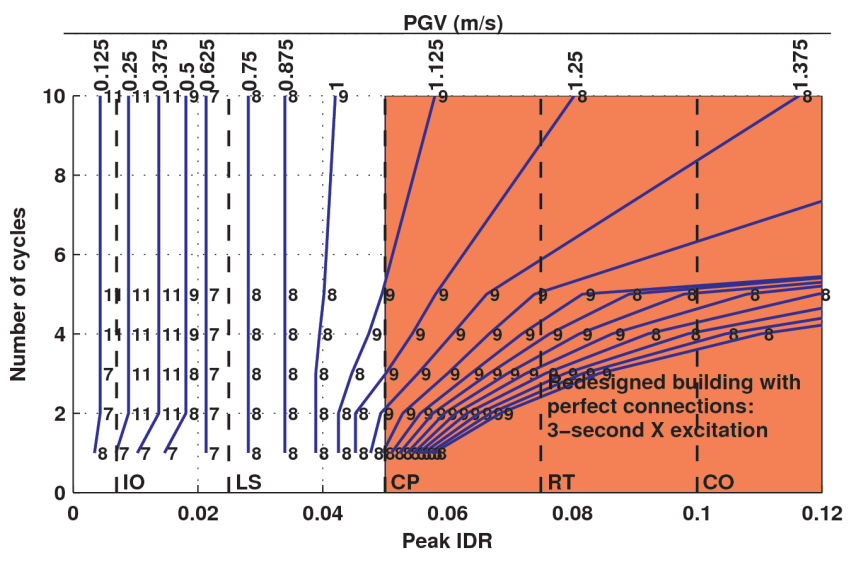

(b)

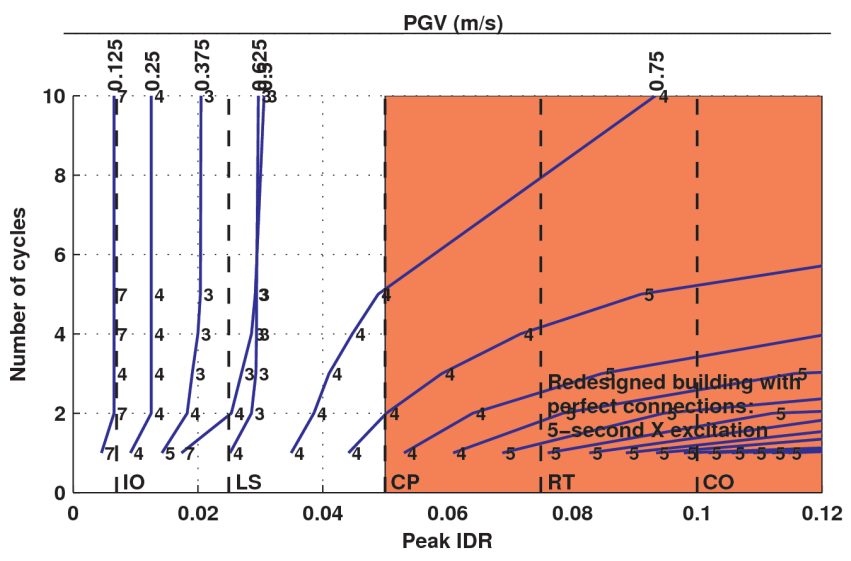

(d)

Figure 16: Peak transient interstory drift ratio (IDR) is shown plotted against the number of cycles $(N)$ in the idealized saw-tooth waveform excitation for the existing [susceptible connections, (a), (c)] and redesigned [perfect connections, (b), (d)] buildings at various levels of peak ground velocity $(P G V)$. Subfigures correspond to excitation periods of $3 \mathrm{~s}$ and $5 \mathrm{~s}$. The one-component ground motion is applied in the building $\mathrm{X}$ direction. The story location where the peak occurs is labeled at each of the 460 [T,PGV] combinations for which analyses were performed. The empirical immediate occupancy (IO), life-safety (LS), collapse prevention $(\mathrm{CP})$, red-tagged (RT), and collapsed (CO) performance levels are marked on the IDR axis.

transient IDR grows with $P G V$ (linearly for moderate period excitation, more rapidly for long period excitation with $T>T_{x}$ ).

These observations can be qualitatively explained by way of the classical analysis of energy budget in multi-story buildings subjected to earthquake excitation [38, 39]. Starting from the governing differential equation of motion and integrating all terms with respect to the structural relative 
displacement vector, $\mathbf{v}$, the equation for energy balance can be written as:

$$
E_{k}(t)+E_{\xi}(t)+E_{s}(t)=E_{I}(t)
$$

where $E_{k}(t)$ is the instantaneous kinetic energy of the system, $E_{\xi}(t)$ is the energy dissipated by viscous forces until time $t, E_{s}(t)$ is the recoverable strain energy stored in the system plus the dissipated hysteretic energy until time $t$, and $E_{I}(t)$ is the energy imparted to the system by the input excitation until time $t$, given by

$$
\begin{aligned}
& E_{k}(t)=\frac{1}{2} \sum_{i=1}^{N_{f}} m_{i}\left[\dot{v}_{i}+\dot{v}_{g}\right]^{2} ; \quad E_{\xi}(t)=\int \mathbf{f}_{\xi}^{T} d \mathbf{v} ; \quad E_{s}(t)=\int \mathbf{f}_{\mathbf{s}}^{T} d \mathbf{v}=\sum_{i=1}^{N_{f}} \int f_{s i} d v_{i} \\
& E_{I}(t)=\int \sum_{i=1}^{N_{f}} m_{i}\left[\ddot{v}_{i}+\ddot{v}_{g}\right] d v_{g}=\int \sum_{i=1}^{N_{f}} m_{i} \ddot{v}_{i} d v_{g}+\frac{1}{2} \sum_{i=1}^{N_{f}} m_{i} \dot{v}_{g}{ }^{2}
\end{aligned}
$$

In the above equations, $\mathbf{f}_{\xi}$ is the damping force vector, $\mathbf{f}_{\mathbf{s}}$ is the restoring force vector, $m_{i}$ is the mass of floor $i$ and $N_{f}$ is the number of floors in the building. $v_{i}, \dot{v}_{i}$, and $\ddot{v}_{i}$ are the displacement, velocity and acceleration, respectively, of floor $i$ relative to the ground. $v_{g}, v_{g}$, and $\ddot{v}_{g}$ are the ground displacement, velocity, and acceleration respectively. $E_{I}$ is the total work done by all the inertial forces (base shear) on the foundation (displacing through a displacement equal to the ground displacement). In other words, it is the energy imparted to the structure during seismic shaking (e.g., [2, 9, 26, 37]). If the input excitation period is much shorter than that of the structure, we have $v_{i} \approx-v_{g}$; as a result, $E_{I} \approx 0$. For the long-period buildings of this study, the energy imparted from short-period excitation is small and the peak transient IDR must consequently be quite small. If the input excitation period is much longer than that of the structure, $v_{i} \approx 0$, and $E_{I} \approx \frac{1}{2} \sum_{i=1}^{N_{f}} m_{i} \dot{v}_{g}^{2}$, i.e., the input excitation energy is proportional to the square of the ground velocity. It is clear from this analysis that for the 
long-period structures of this study, only long-period ground motion can induce a strong response. This explains why collapse-level response is induced only by ground motions with periods longer than the fundamental period of the building (for single-cycle excitation). Moreover, for long period motion, the structural response degrades rapidly with $P G V$ due to the quadratic relationship between input energy and $P G V$. If the intensity of shaking $(P G V)$ is very strong, then the period does not have to be as long to induce collapse-level response. Alternately, within certain limits, a longer period motion relative to the building fundamental period requires a smaller $P G V$ to cause collapse-level response. This explains the lower $P G V$ thresholds required for collapse-level IDR in the $\mathrm{Y}$ direction of the existing building (perfect connections) compared to the $\mathrm{X}$ direction $\left(T_{y}=4.26 s<T_{x}=4.52 s\right)$. Of course, if ground motion period is too long (greater than, say, twice or thrice the fundamental period of the building), then loading is almost static and does not induce strong enough dynamic response. It should be noted that the energy balance analysis is not appropriate for excitation velocities that are extreme where conservation of momentum may be more applicable. However, peak ground velocity from earthquakes seldom exceeds $2.5 \mathrm{~m} / \mathrm{s}$ and energy balance would generally be applicable.

\section{4.. Limitations of the Study}

(a) The findings of the study are based on analyses of just two moment frame buildings in the 15-20 story class. These buildings cannot be realistically considered to cover the entire class of steel moment frame buildings. Having said this, the periods and strengths of these two buildings are significantly different, the existing building has a prominent torsional eccentricity whereas this is eliminated in the redesigned building, and different levels of vulnerability to fracture have been considered. Thus, the models analyzed do cover a broad spectrum of features within this class of structures. Furthermore, the sensitivity of structural response of these models is consistent with theoretical energy balance 
predictions. The strong theoretical basis for the findings suggest that they are robust and may be broadly applicable to the entire class of tall steel moment frame buildings. However, further studies are needed to confirm this.

(b) The parametric analyses are conducted using single component excitation. The results are thus applicable to ground motions with the strong component oriented in either one of the two principal directions of the buildings (or lateral force-resisting system). If the strongest shaking is at a $45^{\circ}$ angle with respect to either principal direction of the building the peak transient IDR response of the structure may be estimated as the sum of the square root of the squares of peak transient IDR from the two components of ground motion in the building principal directions.

(c) Ground velocity waveforms with positive and negative phases of different amplitudes or with an unequal number of positive and negative phases have not been considered in the parametric analyses.

(d) As with any modeling techniques, the FRAME3D models of the buildings have limitations too: (i) Composite action of moment-frame beams has not been included; (ii) Damage to floor slabs is not modeled; (iii) Floor framing beams that support the dead weight of the floors are not modeled. While they are typically much shallower and smaller than the moment frame beams and, so, assumed pinconnected, in reality they do offer partial restraint; (iv) Some critical failure modes such as local flange buckling of I-sections are not included in the structural modeling; (v) Column splices have not been modeled. These splices are weak points and could fail especially if the column goes into tension during the earthquake; (vi) Stiffness and strength of partitions, and stair \& elevator enclosures is not included; (vii) The structure foundations have not been included in the structural models. Soilstructure interaction is not included in the analyses. 


\section{5.. Conclusions}

Parametric analysis of two 18-story steel moment frame buildings and their variants are conducted to study their sensitivity to ground motion features. The first is an existing building $\left(T_{x}=4.52 s, T_{y}=\right.$ $4.26 s, T_{\phi}=2.69 \mathrm{~s}$ ) designed according to the $1982 \mathrm{UBC}$. The second has the same configuration, but is redesigned according to the $1997 \mathrm{UBC}\left(T_{x+y-}=4.05 s, T_{x+y+}=3.85 s, T_{\phi}=2.60 s\right)$. Four cases are considered - existing building with susceptible connections excited in the $\mathrm{X}$ direction, existing building with perfect connections excited separately in $\mathrm{X}$ and $\mathrm{Y}$ directions, and redesigned building with perfect connections excited in the $\mathrm{X}$ direction. Ground velocity waveforms are idealized as sawtooth-like wave-trains, characterized by three parameters- a period $T$, an amplitude $P G V$ (peak ground velocity), and a duration represented by the number of cycles $N$. The structural response under a suite of real records matches closely with the response under the corresponding best-fitting idealized waveforms. The four building models are analyzed under a suite of idealized ground motion waveforms applied in either direction and the results are stored in a database. $T$ is varied between $0.5 \mathrm{~s}-6.0 \mathrm{~s}, P G V$ is varied between $0.125 \mathrm{~m} / \mathrm{s}-2.5 \mathrm{~m} / \mathrm{s}$ and $N$ is varied between $1-5.1$-cycle (near-source) ground motion with pulse-periods longer than $4.5 \mathrm{~s}$ and $P G V$ greater than $1.625 \mathrm{~m} / \mathrm{s}$, and 3-cycle motion with cycleperiods longer than $3.25 \mathrm{~s}$ and $P G V$ greater than $0.75 \mathrm{~m} / \mathrm{s}$ cause collapse in the buildings considered in this study. Under short period excitation $(T<1.5 s)$. the peak transient interstory drift ratio (IDR) saturates to a value below the collapse prevention $(\mathrm{CP})$ performance limit with increasing $P G V$, i.e., collapse can only be caused by long-period ground motion. Under longer period ground motion, the peak transient IDR grows with $P G V$ (linearly for moderately long-period excitation, more rapidly for long-period excitation with $T>T_{x}$ ). Collapse risk is negligible/minor if $P G V<0.5 \mathrm{~m} / \mathrm{s}$ or $T<1.5 \mathrm{~s}$ for $N \leq 5$ for all four building models. Partial (and perhaps complete) collapse is almost certain to 
occur in all four models if ground excitation $T>5 s, P G V>1 \mathrm{~m} / \mathrm{s}$, and $N>1$. These findings are qualitatively explained using a classical energy balance analysis for multi-story buildings under earthquake excitation. The number of cycles of ground excitation has minimal impact in cases where peak transient IDR is below the CP limit. If the peak transient IDR exceeds the CP limit, degradation is swift with increasing number of cycles for both susceptible as well as perfect-connection models.

\section{6.. Acknowledgments}

The authors would like to express their deep gratitude to Professor Paul Jennings of the California Institute of Technology and two anonymous reviewers for their thorough review of this work. Their insightful comments have helped refine this article appreciably. This study was funded in part by the U.S. National Earthquake Hazard Reduction Program (NEHRP award number G09AP00063).

\section{REFERENCES}

[1] Beck, J. L., AND Hall, J. F. Structural damage in Mexico city. Geophysical Research Letters 13 (1986), 589-592.

[2] Berg, G. V., And Thomaides, S. S. Energy consumption by structures in strong-motion earthquakes. In Proceedings of the $2^{\text {nd }}$ World Conference on Earthquake Engineering, Tokyo, Japan (1960), pp. 681-696.

[3] Carlson, A. Three-dimensional nonlinear inelastic analysis of steel moment frame buildings damaged by earthquake excitations. Tech. Rep. EERL 99-02, Earthquake Engineering Research Laboratory, California Institute of Technology, Pasadena, California, USA, 1999.

[4] Challa, V. R. M., AND Hall, J. F. Earthquake collapse analysis of steel frames. Earthquake Engineering and Structural Dynamics 23, 11 (1994), 1199-1218. 
[5] Chi, W., El-Tawil, S., Deierlein, G. G., And Abel, J. F. Inelastic analyses of a 17-story framed building damaged during northridge. Engineering Structures 20, 4-6 (1998), 481-495.

[6] FEMA. Prestandard and Commentary for the Seismic Rehabilitation of Buildings. FEMA-356. Federal Emergency Management Agency, USA, 2000.

[7] FEMA. Recommended Seismic Evaluation and Upgrade Criteria for Existing Welded Steel Moment Frame Buildings. FEMA-351. Federal Emergency Management Agency, USA, 2000.

[8] FEMA. State of the Art Report on Past Performance of Steel Moment Frame Buildings in Earthquakes. FEMA-355E. Federal Emergency Management Agency, USA, 2000.

[9] Goel, S. C., AND BerG, G. V. Inelastic earthquake response of tall steel frames. Journal of the Structural Division, ASCE 94, 8 (1968), 1834-1907.

[10] Gupta, A., And Krawinkler, H. Behavior of ductile SMRFs at various seismic hazard levels. Journal of Structural Engineering 126, 1 (2000), 98-107.

[11] Gupta, A., AND Krawinkler, H. Estimation of seismic drift demands for frame structures. Earthquake Engineering and Structural Dynamics 29, 9 (2000), 1287-1305.

[12] Hall, J. F., Heaton, T. H., Halling, M. W., and Wald, D. J. Near-source ground motion and its effects on flexible buildings. Earthquake Spectra 11, 4 (1995), 569-605.

[13] Iwata, Y., Sugimoto, H., And Kuwamura, H. Reparability limit of steel structural buildings based on the actual data of hyogoken-nanbu earthquake. Technical Memorandum of Public Works Research Institute 4022 (2006), 86-95.

[14] KRISHNAN, S. FRAME3D - A program for three-dimensional nonlinear time-history analysis of steel buildings: User guide. Tech. Rep. EERL 2003-03, Earthquake Engineering Research Laboratory, California Institute of Technology, Pasadena, California, USA, 2003.

[15] KRISHNAN, S. Case studies of damage to 19-storey irregular steel moment frame buildings under 
near-source ground motion. Earthquake Engineering and Structural Dynamics 36, 7 (2007), $861-885$.

[16] KRISHNAN, S. FRAME3D V2.0 - A program for the three-dimensional nonlinear time-history analysis of steel structures: User guide. Tech. Rep. EERL 2009-04, Earthquake Engineering Research Laboratory, California Institute of Technology, Pasadena, California, USA, 2009.

[17] Krishnan, S. The modified elastofiber element for steel slender column and brace modeling. Journal of Structural Engineering 136, 11 (2010), 1350-1366.

[18] Krishnan, S., AND Hall, J. F. Modeling steel frame buildings in three dimensions - Part I: Panel zone and plastic hinge beam elements. Journal of Engineering Mechanics 132, 4 (2006), $345-358$.

[19] Krishnan, S., AND Hall, J. F. Modeling steel frame buildings in three dimensions - Part II: Elastofiber beam element and examples. Journal of Engineering Mechanics 132, 4 (2006), $359-374$.

[20] Krishnan, S., Ji, C., Komatitsch, D., AND Tromp, J. Performance of 18-story steel moment frame buildings during a large San Andreas earthquake - a Southern California-wide end-to-end simulation. Tech. Rep. EERL 2005-01, http://caltecheerl.library.caltech.edu, Earthquake Engineering Research Laboratory, California Institute of Technology, Pasadena, California, USA, 2005.

[21] Krishnan, S., Ji, C., Komatitsch, D., And Tromp, J. Performance of two 18-story steel moment frame buildings in southern California during two large simulated San Andreas earthquakes. Earthquake Spectra 22, 4 (2006), 1035-1061.

[22] Krishnan, S., AND Muto, M. Mechanism of collapse, sensitivity to ground motion features, and rapid estimation of the response of tall steel moment frame buildings to earthquake excitation. 
Tech. Rep. EERL 2011-02, Earthquake Engineering Research Laboratory, California Institute of Technology, Pasadena, California, USA, 2011.

[23] KRishnan, S., And Muto, M. Mechanism of collapse of tall steel moment frame buildings under earthquake excitation. Journal of Structural Engineering In Print (2012).

[24] Krishnan, S., Muto, M., Mourhatch, R., Buörnsson, A. B., And Siriki, H. Ruptureto-rafters simulations: Unifying science and engineering for earthquake hazard mitigation. Special Issue on Earthquake Engineering Simulation, IEEE Computing in Science and Engineering (CiSE) 13, 4 (2011), 28-43.

[25] MacRae, G. A. Parametric study on the effect of ground motion intensity and dynamic characteristics on seismic demands in steel moment resisting frames. Tech. Rep. SAC/BD-99/01, Structural Engineers Association of California, Applied Technology Council, and California Universities for Research in Earthquake Engineering, USA, 1999.

[26] Mahin, S. A., And Lin, J. Construction of inelastic response spectrum for single degree of freedom system. Tech. Rep. UCB/EERC-83-17, Earthquake Engineering Research Center, University of California, Berkeley, California, USA, 1983.

[27] Medina, R. A., And Krawinkler, H. Seismic demands for nondeteriorating frame structures and their dependence on ground motions. Tech. Rep. BLUME-144, The John A. Blume Earthquake Engineering Center, Stanford, California, USA, 2003.

[28] Medina, R. A., And Krawinkler, H. Evaluation of drift demands for the seismic performance assessment of frames. Journal of Structural Engineering 131, 7 (2005), 1003-1013.

[29] Muto, M., And KRishnan, S. Hope for the best, prepare for the worst: Response of tall steel buildings to the shakeout scenario earthquake. Earthquake Spectra 27, 2 (2011), 375-398.

[30] Olsen, A. H., AagaArd, B. T., and Heaton, T. H. Long-period building response to 
earthquakes in the San Francisco bay area. Bulletin of the Seismological Society of America 98, 2 (2008), 1047-1065.

[31] Osteraas, J. D., AND Krawinkler, H. Strength and ductility considerations in seismic design. Tech. Rep. BLUME-90, 1990-08, The John A. Blume Earthquake Engineering Center, Stanford, California, USA, 1990.

[32] SAC. Analytical and field investigations of buildings affected by the Northridge earthquake of January 17, 1994 - Part 1. Tech. Rep. SAC 95-04, Part 1, Structural Engineers Association of California, Applied Technology Council, and California Universities for Research in Earthquake Engineering, USA, 1995.

[33] SHAw, J. H., AND SUPPE, J. Earthquake hazards of active blind-thrust faults under the central Los Angeles basin. Journal of Geophysical Research 101, B4 (1996), 8623-8642.

[34] SIEH, K. E. A study of late Holocene displacement history along the south-central reach of the San Andreas fault. Tech. Rep. Ph.D. Dissertation, Stanford University, California, USA, 1977.

[35] SieH, K. E. Pre-historic large earthquakes produced by slip on the San Andreas fault at Pallett creek, California. Journal of Geophysical Research 83 (1978), 3907-3939.

[36] Somerville, P., Smith, N., Punyamurthula, S., And Sun, J. Development of ground motion time histories for phase 2 of the FEMA/SAC steel project. Tech. Rep. SAC/BD-97/04, Structural Engineers Association of California, Applied Technology Council, and California Universities for Research in Earthquake Engineering, USA, 1997.

[37] UANG, C.-M., AND BERTERo, V. V. Earthquake simulation tests and associated studies of a 0.3-scale model of a six-story concentrically braced structure. Tech. Rep. UCB/EERC-86-10, Earthquake Engineering Research Center, University of California, Berkeley, California, USA, 1986. 
[38] UANG, C.-M., AND BERTERO, V. V. Use of energy as a design criterion in earthquake-resistant design. Tech. Rep. UCB/EERC-88-18, Earthquake Engineering Research Center, University of California, Berkeley, California, USA, 1988.

[39] UANG, C.-M., AND Bertero, V. V. Evaluation of seismic energy in structures. Earthquake Engineering and Structural Dynamics 19, 1 (1990), 77-90.

[40] Vamvatsikos, D., And Cornell, C. A. Incremental dynamic analysis. Earthquake Engineering and Structural Dynamics 31, 3 (2001), 491-514.

[41] Wald, D. J., Heaton, T. H., And Hudnut, K. W. The slip history of the 1994 Northridge, California, earthquake determined from strong-motion, teleseismic, GPS, and leveling data. Bulletin of the Seismological Society of America 86 (1996), S49-S70.

[42] Watson, D. F. Contouring: A Guide to the Analysis and Display of Spatial Data. Pergamon, 1994.

[43] YANG, J. Nonlinear responses of high-rise buildings in giant subduction earthquakes. Tech. Rep. Ph.D. Dissertation, California Institute of Technology, Pasadena, California, USA, 2009.

[44] Zareian, F., AND Krawinkler, H. Structural system parameter selection based on collapse potential of buildings in earthquakes. Journal of Structural Engineering 136, 8 (2010), 933-943.

[45] Zareian, F., Krawinkler, H., Ibarra, L., And Lignos, D. Basic concepts and performance measures in prediction of collapse of buildings under earthquake ground motions. The Structural Design of Tall and Special Buildings 19, 1-2 (2010), 167-181.

[46] Zareian, F., Lignos, D., And Krawinkler, H. Evaluation of seismic collapse performance of steel special moment resisting frames using FEMA P695 (ATC-63) methodology. In Proceedings of the 2010 Structures Congress, ASCE (2010). 